SÁNCHEZ, María: "Primeros pasos de la neuroimagen en el proceso penal estadounidense".

Polít. Crim. Vol. 15, No 29 (Julio 2020), Art. 8, pp. 230-258

[http://politcrim.com/wp-content/uploads/2020/07/Vol15N29A8.pdf]

\title{
Primeros pasos de la neuroimagen en el proceso penal estadounidense*
}

\author{
First steps of neuroimaging in American criminal procedure
}

\author{
María Sánchez Vilanova \\ Profesora Ayudante Doctora. Universidad de Valencia \\ maria.sanchez-vilanova@uv.es
}

\section{Resumen}

En el presente estudio se efectúa una revisión de la aportación de las pruebas de neuroimagen en el proceso penal estadounidense, cuya contribución varía en gran medida en función de la etapa del proceso en la que sean alegadas: mientras los datos neurocognitivos no tienen prácticamente relevancia en la fase de determinación de la competencia o de culpabilidad, en la de sentencia se están convirtiendo en una poderosa arma para la mitigación, sobre todo en aquellos casos en los que se discute la pena capital. No obstante, como se concluirá, sería en esta fase de culpabilidad, como fundamento de la defensa incompleta de capacidad disminuida cuando se discuten trastornos mentales, especialmente cuando estos afecten a la esfera de la personalidad, donde estas pruebas podrían tener una mayor repercusión judicial, en contraste con sus usos más mediáticos y, a la vez, desafortunados, como el protagonizado por la famosa técnica de la detección de mentiras.

Palabras clave: Neuroderecho, neuroimagen, fase de sentencia, insanity defense, pena capital.

\begin{abstract}
The present study reviews the contribution of neuroimaging tests in the American criminal process, whose contribution varies greatly depending on the stage of the process in which they are used: while the neurocognitive data have practically no relevance in the phase of competency to stand trial or for culpability, in the sentencing phase they are becoming a powerful weapon for mitigation, especially in those cases in which is discussed the death penalty. However, as we will conclude, it would be in this guilt phase, as the basis for the incomplete defense of diminished capacity when mental disorders are discussed, especially when they affect the sphere of personality, where these tests could have a greater judicial impact, in contrast with its more mediatic uses and, at the same time, unfortunate, like the one carried out by the famous lie detection technique.
\end{abstract}

Keywords: neurolaw, neuroimaging, judgement phase, insanity defense, capital punishment.

\footnotetext{
* Este artículo ha sido elaborado en el marco del Proyecto "Derecho Penal de la peligrosidad: Tutela y garantía de los Derechos Fundamentales" (DER2017-86336-R), concedido por el Ministerio de Economía y Competitividad.
} 


\section{Polít. Crim. Vol. 15, № 29 (Julio 2020), Art. 8, pp. 230-258 \\ [http://politcrim.com/wp-content/uploads/2020/07/Vol15N29A8.pdf]}

\section{Introducción: aproximación al neuroderecho}

En los últimos años la repercusión de la Neurociencia en el derecho ha alcanzado una dimensión internacional ${ }^{1}$, y si bien su aplicabilidad real depende del sistema legal de cada país, cuando se discute su introducción parece que, en el fondo de la cuestión, en todos los estados resuenan los mismos argumentos y contraargumentos. Grosso modo, apostar por el uso de estas nuevas tecnologías, en base a su utilidad para mejorar la respuesta que se dispensa en casos particulares, conforme con un entendimiento compatibilista de los avances neurocientíficos, o rechazar de entrada su introducción al concebir que los conocimientos que la ciencia del encéfalo arroja aniquilan la libertad que fundamenta cualquier sistema sancionador, adhiriéndose al denominado "determinismo duro". Pues bien, debido a las particularidades de su sistema, los Estados Unidos de América (en adelante, "EUA") han sido uno de los países pioneros en su utilización, encontrando interesantes casos en los que los datos aportados por las técnicas de neuroimagen han sido debatidos en el proceso penal, y a los cuales se hará referencia en el presente estudio.

En aras de facilitar al lector la comprensión del tema que se presenta, se empezará por considerar el modesto origen del Neuroderecho, ${ }^{2}$ ligado al Derecho civil. Sherrod, Anderson y Tyron ${ }^{3}$ acuñaron este término durante los años noventa del pasado siglo XX para describir los cursos convergentes de la Neuropsicología y el sistema legal al explicar la cada vez mayor influencia de los testimonios de los expertos neuropsicólogos en las demandas civiles de individuos con lesiones cerebrales, en un momento en que aquella embrionaria rama no tenía todavía pretensión alguna de cambiar la doctrina penal. Sin embargo, lo cierto es que desde el inicio despertó cierta fascinación debido a su supuesta capacidad para describir la personalidad de los individuos en función de los aspectos estructurales y funcionales del cerebro ${ }^{4}$. Los avances en Neurociencia cognitiva, especialmente los adelantos en las diferentes técnicas de neuroimagen funcional, han supuesto un enorme progreso en la comprensión de cómo funciona la mente, por lo que cada vez son más recurrentes los estudios sobre las implicaciones de la Neurociencia en diferentes áreas del derecho y la política, sin olvidar su relevancia en la economía, ${ }^{5}$ uno de los campos más prolíficos en publicaciones al respecto. En todo caso, en relación a sus implicaciones jurídicas, el impacto de la Neurociencia en el Derecho civil ${ }^{6}$ ha sido posiblemente mayor que en el Derecho Penal. A modo ejemplificativo, los resultados obtenidos mediante diferentes técnicas de neuroimagen han sido presentados como prueba en algunos importantes procesos civiles norteamericanos, donde destacan, entre

\footnotetext{
${ }^{1}$ Concretamente, desde el año 2004, con la aparición del texto "Neuroscience and the Law, Brain, Mind and the Scales of Justice", las discusiones que vinculan Neurociencia y Derecho ha ido en aumento. Al respecto, consultar: GARLAND (2004), p. 71.

2 Aunque la mayoría de los autores se refieren a esta nueva disciplina como "neuroderecho" (neurolaw), algunos cuestionan tal denominación al entender que sería más precisa su denominación como "derecho cognitivo", teniendo en cuenta que las técnicas que la Neurociencia cognitiva

proporciona tienen como objetivo analizar los principios de subjetividad en relación a los comportamientos relevantes legalmente. Ponen de relieve estos extremos, entre otros: ARNAUDO (2010), p. 8; PARDO y PATTERSON (2010), pp. 1212-1242.

${ }^{3}$ SHERROD y ANDERSON (1991), pp. 293-305.

${ }^{4}$ En estos primeros pasos conviene destacar el papel de la norteamericana Margaret Gruter, una de las pioneras en destacar la importancia de un trabajo interdisciplinario en el sistema legal si se querían resultados eficaces. Actualmente, el Instituto Gruter es una comunidad de investigación que promueve la colaboración entre diferentes disciplinas para mejorar la comprensión de la interacción entre el Derecho, las instituciones y el comportamiento humano. Al respecto, consultar: ERICKSON (2010), pp. 27-77, 35.

${ }^{5}$ Entre otros: HOFFMAN (2004), passim; JONES y SHEN (2011), passim; MIDGLEY (2004), passim.

${ }^{6}$ CARTER (2006), passim; JONES (2014), p. 45; JONES y BROSNAN (2008), p. 49.
} 


\section{SÁNCHEZ, María: "Primeros pasos de la neuroimagen en el proceso penal estadounidense".}

muchos otros, el caso Van Middlesworth v. Century Bank \& Trust Co., ${ }^{7}$ en el que se aportó una resonancia magnética para fundamentar la incompetencia contractual en la venta de unas tierras, el caso Fini v. Gen. Motors Corp. ${ }^{8}$ un proceso en el que se solicitó una Tomografía Axial Computerizada (en adelante, "TAC") para ayudar a determinar el grado de lesiones cerebrales en un accidente de tráfico, o, finalmente, en Boyd v. Bert Bell/Pete Rozelle $^{9}$ fue presentada una TAC para demostrar el derecho a beneficios por una incapacidad neurodegenerativa. No obstante, como Farahany ${ }^{10}$ concluye en su estudio del año 2016, la alegación de pruebas neurocientíficas para mitigar la responsabilidad es cada vez mayor, hecho que ha posibilitado la mejora del sistema de justicia penal. Para terminar, hay que mencionar las cuestiones éticas que de esta disciplina se derivan, las cuales están adquiriendo una enorme importancia y han propiciado el surgimiento de una nueva rama de la bioética: la neuroética. ${ }^{11}$

Ahora bien, a pesar del rápido incremento en el abordaje jurídico sobre las posibilidades de alegación de tales pruebas en los juicios penales, no queda claro todavía cómo el sistema legal de los EUA resolverá los desafíos que estas nuevas aplicaciones plantean. No en balde, algunos autores advierten de los peligros que la introducción de estas técnicas sin apenas estudios al respecto suponen, recordando que el sistema legal estadounidense admitió en algunos momentos históricos la llamada "ciencia basura", con consecuencias verdaderamente preocupantes. ${ }^{12}$ Con independencia de ello, con el apoyo institucional de muchos de los principales centros de investigación, así como el soporte de la Fundación MacArthur, ${ }^{13}$ entre otras fundaciones privadas y organismos de financiación pública, como se avanzó, los EUA se han convertido en uno de los países precursores que más están contribuyendo en la evolución internacional del Neuroderecho. Precisamente para hacer frente a algunos de estos desafíos, la Fundación Mac Arthur creó en el año 2007 el Proyecto de Ley y Neurociencia (Research Network on Law and Neuroscience), que cuatro años más tarde desembocó en la creación de la Red de Investigación sobre Derecho y Neurociencia; centros que, con sede en la Facultad de Derecho de la Universidad de Vanderbilt, han fomentado la investigación interdisciplinar en este país, y han posibilitado, por ejemplo, la elaboración de la guía en Derecho y Neurociencia, que ha sido divulgada entre los jueces norteamericanos, así como el primer libro de casos sobre Derecho y Neurociencia para estudiantes de Derecho ${ }^{1415}$.

\footnotetext{
${ }^{7}$ No. 215512, 2000 WL 33421451, at 1-2 (Mich. Ct. App. May 5, 2000).

${ }^{8}$ No. 227592, 2003 WL 1861025, at 2-3 (Mich. Ct. App. Apr. 8, 2003).

${ }^{9} 410$ F.3d 1173, 1174 (9th Cir. 2005).

${ }^{10}$ FARAHANY (2016), passim.

11 FARAH (2002); ILLES y BIRD (2006), pp. 511-517; MORENO (2003), pp. 149-153; ROSKIES, (2008), passim.

12 MEYER (2009), passim. Una aproximación a la introducción de la conocida como "ciencia basura" en los tribunales estadounidenses en: EHRLICH y FELDMAN (2007), passim.

${ }^{13} \mathrm{Al}$ respecto, consultar: https://www.macfound.org/ [visitado el 25/06/2020].

${ }^{14}$ JONES (2014), passim.

15 De hecho, a pesar de la juventud del campo, en varias escuelas de Derecho estadounidenses se han impartido cursos de Derecho y Neurociencia. Además, en los últimos años algunas de las universidades más prestigiosas tienen también proyectos de Neuroderecho, como por ejemplo la Universidad de Harvard, con el Proyecto de Derecho y Ciencias de la mente ("Project on Law and Mind Sciences"), cuyo objetivo es el estudio de la aplicación de las nuevas técnicas de neuroimagen en el proceso judicial, o la Universidad de Stanford, con un Proyecto de integración del Derecho y la Neurociencia (Integrating Law \& Neuroscience) que pretende ayudar a resolver las difíciles cuestiones legales y éticas suscitadas por esta disciplina, al igual que el Centro de Neurociencia y Sociedad (Center for Neuroscience \& Society), de la Universidad de Pensilvania. Además, desde 2007 el proyecto de la Fundación Mac Arthur se ha asociado con el Instituto Gruter para la investigación del Derecho y del Comportamiento (Gruter Institute for Law and Behavioral Research), el Centro Federal Judicial (FJC), el Colegio Nacional de la Magistratura (CNM)
} 


\section{Polít. Crim. Vol. 15, № 29 (Julio 2020), Art. 8, pp. 230-258 \\ [http://politcrim.com/wp-content/uploads/2020/07/Vol15N29A8.pdf]}

No pretenden las páginas que siguen efectuar un análisis exhaustivo de todos los usos de la neuroimagen en el proceso penal estadounidense, sino que se acomete un objetivo más modesto, como es la valoración de su importancia como pruebas complementarias cuando se discuta la apreciación de la insanity defense ${ }^{16}$ en casos de trastornos mentales, especialmente ante trastornos de la personalidad. Para ello, se ha entendido imprescindible efectuar un breve repaso de esta categoría, analizando las cuatro pruebas que durante su historia han gozado de apoyo, junto con las limitaciones de su interpretación actual. Asimismo, se evidenciarán las posibilidades disímiles de prosperar de las que estas pruebas disponen en función de la fase del proceso en la que se presentan. Aunque las pruebas de neuroimagen llevan años alegándose en el proceso penal estadounidense, su interpretación no está libre de controversias, y mientras los datos neurocognitivos no tienen prácticamente relevancia en la fase de determinación de la competencia o en la de culpabilidad, en la de sentencia, concretamente en los casos en los que se debate la pena capital, están adquiriendo una enorme importancia, debido a la ausencia de las férreas exigencias existentes en las demás etapas, lo cual ha permitido, en no pocos casos, fundamentar minoraciones de responsabilidad. Empero, como en las conclusiones se argumentará, se entiende que posiblemente fuera en la fase de culpabilidad, siempre que fuera reformada la defensa incompleta de capacidad disminuida (diminished responsability) como defensa general conforme con la propuesta de Morse, ${ }^{17}$ donde más relevancia y utilidad tendrían estas pruebas de neuroimagen, especialmente en supuestos de trastornos controvertidos como los de la personalidad.

Para terminar, se estima imprescindible hacer referencia a uno de los usos más conocidos y, a la vez, más desafortundados de la neuroimagen en el proceso penal a nivel internacional: la famosa prueba de la detección de mentiras, con creciente protagonismo no solo en el continente norteamericano, sino también en países como Australia, Singapur o India, que se convirtió en el primer país del mundo en condenar a un acusado de asesinato en base a que un escáner cerebral que determinaba un "conocimiento experimental o de memoria" del acusado respecto del crimen. ${ }^{18}$ Concretamente, estos nuevos instrumentos de medición permiten observar la actividad cerebral mientras se ejecuta una determinada tarea de una forma mucho más precisa que otros métodos, como por ejemplo el conocido polígrado. No obstante, en contraste con este, estos procedimientos de neuroimagen no miden las reacciones físicas, sino que tan solo muestran la actividad cerebral de forma indirecta, por lo que, realmente, su uso no indica un sentimiento de veracidad o falsedad, sino que muestran exclusivamente la función cerebral de un pensamiento ${ }^{19}$; unas limitaciones que parece que son pasadas por alto en ciertos ámbitos, pese a que la mayoria de neurocientíficos se muestren contrarios a su uso

\footnotetext{
y la Asociación Americana para el Avance de la Ciencia (AAAS), patrocinando grandes conferencias a las que acuden cientos de jueces estadounidenses y organizando numerosos programas de Neurociencia específicos para este gremio. Véase ANNAS (2007), p. 163; JONES et al. (2014), passim.

${ }^{16} \mathrm{El}$ término insanity (locura), hace referencia a las enfermedades psicóticas graves.

${ }^{17}$ MORSE (2003), pp. 289-308.

18 State of Maharashtra v. Aditi Baldev Sharma, In the court of Sessions Judge, Pune, Sessions Case No. 508/07 1, 3 (June 2008); de hecho, la prensa se ha hecho eco en númerosas ocasiones de estos casos: 1) Emiliano Feresin, Lighter Sentence for Murderer with "Bad Genes". Nature News (Oct. 30, 2009), http://www.nature.com/news/2009/091030/full/news.2009.1050.html [visitado el 25/06/2020]; 2) Anand Giridharadas, India's Novel Use of Brain Scans in Courts Is Debated, N.Y. Times, (Sep. 14, 2008), http://www.nytimes.com/2008/09/15/world/asia/15brainscan.html [visitado el 25/06/2020].

${ }^{19}$ FARWELL et al. (2013), p. 270.
} 
$\operatorname{comercial}^{20}$. Por tanto, como seguidamente se abordará, la neuroimagen tiene más virtualidad como prueba complementaria en la detección de trastornos mentales que, contrariamente, en la detección de mentiras.

\section{Concreción de la relevancia de la neuroimagen en el proceso penal}

\subsection{Cuestiones previas}

Como se adelantó, los EUA han sido uno de los países donde las pruebas neurocientíficas están teniendo mayor acogida en diferentes contextos legales ${ }^{21}$, lo que se explica por el particular funcionamiento de su sistema ${ }^{22}$. En este sentido, conviene recordar que de la teoría del delito del sistema penal anglosajón emanan dos elementos constitutivos cuya ausencia impide la imposición de una pena: el actus reus —elemento externo-, y el mens rea - elemento interno- - Y, si bien como destaca Piña Rochefort, la definición del delito anglosajona es la expresión correlativa al "tipo de injusto" de la formulación continental, lo cierto es que en la misma se prevén circunstancias en las que, aun concurriendo los elementos de la definición, no se afirma la responsabilidad del agente ${ }^{23}$. Ello se debe a que se concibe el sistema estructurado sobre el esquema de regla-excepción, por lo que no es relevante cuál sea el motivo por el que la regla no se aplique, sino que simplemente importa el hecho de que esta no sea aplicada. Y es precisamente en las defensas, independientes del mens rea, donde las técnicas de neuroimagen han podido tener una aplicación real en el proceso, pues, al final, como Morse y Roskies afirman, la neuroimagen no puede detectar en el momento de la comisión de los hechos los concretos estados mentales, ${ }^{24}$ como los partidarios de su uso en el famoso polígrafo pretenden.

En lo que se refiere a la concreta acogida de las técnicas neurocientíficas como pruebas en el proceso penal, el sistema estadounidense brindó durante la primera década del siglo XXI algunos casos pioneros. Así, al filo de la primera mitad destaca el caso Ropper $v$. Simmons, ${ }^{25}$ uno de los primeros juicios en los que la Corte Suprema (en adelante, "CS")

\footnotetext{
${ }^{20}$ Aunque la literatura al respecto es cada vez más abundante, la mayoría de autores ponen al descubierto sus importantes limitaciones y los problemas de su uso en el terreno forense. Al respecto, consultar, entre otros: AAMODT y CISTER (2006), pp. 9-10; AMIRIAN (2013), passim; BOND y DE PAULO,

(2008), passim; CHURCH (2012), passim; GREENE y PAXTON (2009), passim; PARDO y PATTERSON (2010), passim; WAGNER (2010), pp. 13-14.

${ }^{21}$ Distintos indicadores revelan un rápido crecimiento del emergente Neuroderecho en los EUA. A modo informativo, el número de casos en los que ha sido alegada la prueba neurocientífica en los tribunales estadounidenses se duplicó de 2006 a 2009. Además, desde la década del 2000, el número de publicaciones en inglés de artículos jurídicos que incluyen alguna mención a la Neurociencia se ha cuadruplicado. Referencias: JONES y SHEN (2011), passim; LENAMON. (2010), passim.

${ }^{22}$ En cualquier caso, y aunque no es objeto del presente estudio, en el continente europeo la Neurociencia está protagonizando igualmente un enorme desarrollo y comienza a colarse, aunque tímidamente, en la jurisdicción penal. Concretamente, en Italia, la Corte de Apelación de Trieste, en una sentencia de 18 de septiembre de 2009, apreció una disminución en la imputabilidad en base a una supuesta predisposición genética a la agresividad del acusado, conforme con las aportaciones periciales realizadas por dos neurólogos que apuntaban a la existencia de diferentes anomalías detectables en las imágenes cerebrales, junto con la presencia de cinco genes vinculados con el comportamiento violento (incluyendo el gen responsable de la expresión de la enzima MAOA: el famoso "gen del guerrero"). A pesar de ello, como precisa Urruela Mora, el tribunal juzgador se conformó en este caso con acreditar dichas anomalías que explicaban una mayor tendencia del investigado a la agresividad, sin centrarse, no obstante, en si las mismas habían incidido o no en la comisión del delito. URRUELA MORA (2010), pp. 182 y ss.

${ }^{23}$ PIÑA (2002), pp. 13 y ss.

${ }^{24}$ MORSE y ROSKIES (2012), p. 167.

${ }^{25}$ Christopher Simmons se enfrentó a la pena de muerte por el asesinato de Shirley Cook cuando contaba con 17 años, si bien el Tribunal sostuvo finalmente que la ejecución de delincuentes adolescentes violaba
} 


\section{Polít. Crim. Vol. 15, № 29 (Julio 2020), Art. 8, pp. 230-258 \\ [http://politcrim.com/wp-content/uploads/2020/07/Vol15N29A8.pdf]}

consideró la evidencia neurocientífica en la toma de decisión acerca de la relación entre la madurez del investigado y la culpabilidad. Este caso, que se configuró como la pieza inicial de un nuevo entendimiento de la delincuencia juvenil, estableció el precedente de que se debían considerar los estudios neurocientíficos cuando se discutía la imposición de la pena de muerte a menores de edad. Efectivamente, en los EUA la Neurociencia está empezando a ser tenida en cuenta en la política de justicia juvenil, pese a que la estructura federal de este país provoca que, mientras en estados como California se propongan leyes en consonancia con las modernas investigaciones para reducir la dureza de las sanciones, en otros como Kansas o Nebraska, ${ }^{26}$ estos mismos estudios sean utilizados para el fin contrario, aunque cada vez son mayores las repercusiones que la ciencia del cerebro está teniendo para evitar la pena de muerte en menores.

Se tendrá que esperar, en todo caso, al año 2010, para encontrar la primera audiencia probatoria en un tribunal federal sobre la admisibilidad de la tecnología de la RMf en la técnica de la detección de mentiras, la cual fue rechazada en el famoso caso United States v. Semrau, dada la controversia en los resultados de estas mediciones, ${ }^{27}$ mismo año en el que se admitió una electroencelografía cuantitativa (qEEG), que contribuyó a evitar la pena capital en el caso Florida v. Nelson. ${ }^{28}$ Por último, en el caso Graham v. Florida ${ }^{29}$ la

la octava y decimocuarta enmienda, al considerar que los adolescentes tenían mayores dificultades para controlar sus impulsos, por lo que su ejecución iba en contra de los estándares de la decencia que marcan el progreso de una sociedad madura. Lo importante desde la óptica del presente trabajo fue la influencia de los aportes neurocientíficos en esta decisión de inconstitucionalidad, dado que al emitir su veredicto la Corte hizo una referencia a los argumentos aportados por diferentes organizaciones (entre otras la APA American Psychological Association-, o la AMA -American Medical Association-) que destacaban que el cerebro adolescente aún no había finalizado su desarrollo (tal y como de los estudios de neurociencia cognitiva se desprendía), por lo que debían tener una responsabilidad disminuida. Referencias: Roper $v$. Simmons, 543 U.S. 551, 578 (2005). Se puede ver un exhaustivo análisis del caso en: BAIRD (2012), passim.

26 Entre los trabajos que aborda las repercusiones de la neuroimagen en el establecimiento de la responsabilidad de menores, destacan autores como SHUST, que promueven la ampliación de la posibilidad de mitigación hasta los 25 años a la luz de los nuevos conocimientos neurocientíficos. Además, la Red Nacional de Justicia de Menores ha desarrollado una guía completa para los abogados interesados en utilizar técnicas de neuroimagen. Para más información: ARONSON (2007), p. 115; BIRCKHEAD (2011), p. 15; GRUBER y YURGELUN-TODD (2006), p. 321; MARONEY (2010), passim; NATIONAL JUVENILE JUSTICE NETWORK (2012), passim.

${ }^{27}$ En este caso, el acusado contrató para probar que decía la verdad los servicios de una empresa privada (CEPHOS), que le realizó un escáner cerebral tres veces con resultados contradictorios. Ante esto, la audiencia analizó detenidamente la prueba para determinar si podría constituir una base válida para el testimonio de expertos, emitiendo finalmente el juez un informe en el que recomendaba la inadmisión de los resultados conforme a la Reglas Federales de Evidencia 702 y 401, pues, aunque conforme con esta primera regla la metodología utilizada cumplía los dos primeros criterios (esto es, era comprobable y había sido objeto de publicaciones revisadas por pares), estas eran de valor limitado, puesto que no se referían a la distinción entre verdad y mentira en un individuo, sin olvidar que no se conocía la tasa de error, que la edad de Semrau estaba fuera del intervalo ensayado, o que, conforme a la regla 403, el riesgo de perjuicio injusto era sustancialmente mayor que su valor probatorio. Al respecto, consultar: United States v. Semrau, 693 F.3d 510 (6th Cir. 2012).

${ }^{28}$ Aunque Nelson fue declarado culpable de apuñalar a su mujer y violar a sus hijos, por primera vez un tribunal penal estadounidense admitió el análisis que esta prueba proporcionó sobre la lesión cerebral que padecía el acusado, y, como los miembros del jurado afirmaron sin reparos en las entrevistas posteriores, la evidencia neurocientífica ofrecida fue clave en su resolución; como declaraba expresamente uno de ellos: "Después de ver las imágenes del cerebro, estaba convencido de que este tipo tenía algún tipo de problema cerebral". Al respecto, consultar: State v. Grady Nelson, No. F05-00846 (11th Fla. Cir. Ct., 4 Dec 2010). La noticia es accesible en: OVALLE (2010), passim.

${ }^{29}$ El acusado, menor de edad en el momento de los hechos, fue arrestado por intento de robo y acusado como adulto por robo a mano armada, asalto y agresión. Seis meses más tarde se le detuvo nuevamente por robo y allanamiento de morada, motivo por el cual fue condenado finalmente en 2006 a una pena de prisión 


\section{SÁNCHEZ, María: "Primeros pasos de la neuroimagen en el proceso penal estadounidense".}

CS siguió las incipientes directrices del caso Ropper al prohibir que los delincuentes juveniles pudieran ser condenados a cadena perpetua sin libertad condicional por delitos que no fueran de homicidio, e hizo una referencia explícita al desarrollo de la investigación neurocientífica al respecto. Casos que, sin duda, han tenido un gran impacto en la formación del Neuroderecho, puesto que fueron precursores en cuestionar dónde trazar la línea a partir de la cual se podían tener en consideración las pruebas neurocientíficas en las defensas. ${ }^{30}$

Sintetizando, estos ejemplos ponen de manifiesto que la evidencia neurocientífica ya ha llegado a la sala de los tribunales estadounidenses, y, como se ha visto, a una de las jurisdicciones más importantes: la penal. ${ }^{31}$ Pues bien, en estos procesos la evidencia puede ser introducida en la fase de instrucción, para debatir la capacidad del acusado para ser enjuiciado (competency to stand trial), en la fase de culpabilidad o en la de sentencia (sin olvidar, no obstante, los procedimientos posteriores). Con independencia de ello, es esencialmente en esta última fase donde mayor importancia están teniendo estas técnicas, pues en aquellos estados que todavía contemplan la pena de muerte, la fase de sentencia se separa de la de culpabilidad para permitir que las partes aleguen cualquier circunstancia que pudiera ser relevante en la decisión sobre la pena capital, con lo que su admisión, que - reiterando lo dicho en líneas anteriores - no está sujeta a los requisitos de las anteriores etapas, resulta más factible.

A decir verdad, en el ordenamiento jurídico norteamericano los jueces han podido valerse de sus flexibles categorías para la introducción de las pruebas neurológicas, una posibilidad que en los ordenamientos europeos occidentales, con categorías dogmáticas y reglas de admisibilidad más rígidas, resulta mucho más compleja. ${ }^{32}$ Concretamente, uno de los usos que se estima más interesantes de estas (al margen de sus utilidades más mediáticas) ha sido en la insanity defense, si bien, como en el siguiente epígrafe se detallará, también en el common law hay pocas figuras tan controvertidas como la misma, en la que la aplicación de estas nuevas técnicas es mucho más cuidadosa, ${ }^{33}$ especialmente

perpetua. Este caso llegó a la CS, que entendió, según opinión mayoritaria, que la Constitución prohibía la imposición de este tipo de penas a un delincuente juvenil en delitos que no atentasen contra la vida, por lo que anuló la sentencia del Tribunal de $1^{\mathrm{a}}$ instancia conforme con el precedente de Ropper. Referencias: AMERICAN MEDICAL ASSOCIATION (2005). Brief of the American Medical Association et al. as Amici Curiae in Support of Respondent; Graham v. Florida, 560 U.S. 48 (2010); MORSE (2004), passim; Thompson v. Oklahoma, 487 U.S. 815. (1988).

${ }^{30}$ De todos modos, algunos autores destacan que desde mediados de la década de los ochenta estaría abierta la puerta para la introducción de pruebas neurocientíficas: en el caso Ake v. Oklahoma, la CS de los EUA sostuvo la necesidad del testimonio psiquiátrico cuando se alegaba la insanity defense. Y, teniendo en cuenta que la neuroimagen está incluida en el ámbito del testimonio psiquiátrico, estas pruebas podrían ser aportadas. Al respecto, consultar: Ake v. Oklahoma, 470 U.S. 68. (1985); YEON CHOE (2014), pp. 15041505; PATEL (2007), p. 558.

${ }^{31}$ Farahany se hace eco de la rápida tasa de crecimiento de los casos estadounidense en los que es alegada una evidencia neurocientífica, con el doble de alegaciones en 2009. Para más información, consultar: FARAHANY (2011), pp. 485 y ss.

32 De hecho, siguiendo a Romeo Casabona, la alegación de anomalías genéticas en la reducción de responsabilidad se ha producido en los EUA desde finales de los años sesenta. En este sentido se debe recordar los pioneros casos de People v. Farley (Tribunal Superior del Estado de Nueva York, Queens County, de 30 de abril de 1969), o People v. Tanner (Corte de Apelación de California, 1970). Ya en la década de los noventa es interesante en el presente estudio el caso Mobley v. State (1995), en el que la defensa alegó determinadas características genéticas de su cliente, basándose en los estudios de Brunner sobre el MAOA. De todos modos, el tribunal rechazó esta defensa al no contar estos estudios con suficiente apoyo científico. ROMEO CASABONA (2013), p. 427.

${ }^{33}$ DRESSLER (1992), p. 289; FINGARETTE (1972), p. 128; MOORE (1984), passim. 


\section{Polít. Crim. Vol. 15, № 29 (Julio 2020), Art. 8, pp. 230-258 \\ [http://politcrim.com/wp-content/uploads/2020/07/Vol15N29A8.pdf]}

si se tiene en cuenta que en la mayoría de estados la diminished responsability no constituye una defensa. ${ }^{34}$ Esto ha impulsado a que autores como MORSE, de acuerdo precisamente con los nuevos conocimientos neurocientíficos, planteen una figura de responsabilidad disminuida similar en gran medida a la regulación continental de la semiimputabilidad. ${ }^{35}$ Por el contrario, sería muy difícil que gran parte de los trastornos mentales, como por ejemplo los de la personalidad, negaran el mens rea.

En relación con lo anterior, se estima apropiado remarcar en este punto la independencia de las dos figuras a las que el presente trabajo se refiere de forma continua, puesto que, aunque algunos tribunales rechazan la afirmación del mens rea al entender que es una forma menor de la insanity defense, y por lo tanto, una circunstancia atenuante, esto no es más que una confusión: mientras que la insanity defense está basada en la premisa de que el sujeto carece de la capacidad racional requerida, el mens rea no se refiere a esta, sino que alude a la posesión del estado mental requerido por la definición del crimen. Además, aunque la afirmación del mens rea es más fácil de establecer, dado que la misma únicamente requiere una duda razonable por parte del fiscal, mientras que la carga de la prueba en la insanity defense reduce las posibilidades de su apreciación, reiterando las palabras de Morse al respecto, el efecto de un trastorno mental, y menos aún si este afecta a la esfera de la personalidad, en raras ocasiones podrá negar los estados subjetivos que conforman el mens rea, como el propósito, el conocimiento o la imprudencia que son parte de las definiciones de los crímenes. Tales trastornos pueden dar a la gente razones irracionales para formar el mens rea, pero casi nunca interfieren con la formación de ese estado mental. ${ }^{36}$ Por tanto, de acuerdo con estos extremos, la capacidad disminuida que el citado autor plantea para el sistema norteamericano resultaría, como seguidamente se abordará, verdaderamente interesante a los efectos de la presente investigación. De hecho, en el Reino Unido se ha experimentado un importante crecimiento en los últimos diez años de la utilización de estas técnicas para apoyar los recursos contra las sentencias condenatorias por asesinato en las que se alega una responsabilidad disminuida. Sirva, como ejemplo, el caso $R v$. Hanson, ${ }^{37}$ donde se recurrió a la neuroimagen para valorar si el trastorno, en el que todos los expertos coincidieron que sufría el acusado, pudo afectar a su responsabilidad. Sin embargo, a pesar de estos incipientes casos, los tribunales británicos tienden a ser aún más escépticos que los norteamericanos en la utilización de estas técnicas, ${ }^{38}$ como ocurre asimismo en el resto de países europeos, especialmente de tradición continental. Dicho esto, los problemas que subyacen en la mayoría de categorías, explícita o implícitamente, son comunes en ambas tradiciones, y las

\footnotetext{
${ }^{34}$ Concretamente, son cuarenta y seis los estados que acogen esta defensa, aunque, desafortunadamente, algunos estados federales, tras el caso de Hinckley, abolieron esta defensa. En cuatro de ellos (Kansas, Utah, Montreal y Wisconsin) la abolición fue considerada constitucional por sus Tribunales Supremos (no así, en cambio, en Nevada, donde fue declarada inconstitucional). Referencias: PIÑA ROCHEFORT (2002), p. 119, nota 263; State v. Hurst, 606 So. 2d 965, 968 (La. App. 3 Cir. 1992).

35 Puesto que no se debe olvidar, como Piña Rochefort refiere, que la diminished responsability estadounidense no se corresponde propiamente con lo que se denomina defensa general, puesto que su aplicación se encuentra limitada únicamente al delito de asesinato (murder). Esta institución, aunque ya antes era conocida por el derecho escocés, se incorporó al derecho inglés en 1957 a través de la Homicidi Act de ese año, y puede ser alegada por aquel que, cometiendo un asesinato, o participando en su perpetración, sufre tal anormalidad mental, ya emane esta de una malformación o retardo, o de cualquier otra causa intrínseca o inducida por enfermedad o daño, que sustancialmente menoscabe su responsabilidad mental por los actos u omisiones que constituyen la perpetración del delito o la participación en este. PIÑA ROCHEFORT (2002), pp. 123-124.

${ }^{36}$ MORSE (2011), pp. 837-859.

${ }^{37}$ Al respecto consultar: $R v$. Hanson, EWCA Crim 1142 (2005).

${ }^{38} R v$. Hanson, EWCA Crim 1142 (2005).
} 


\section{SÁNCHEZ, María: "Primeros pasos de la neuroimagen en el proceso penal estadounidense".}

soluciones verdaderamente parecidas, pues en el fondo del asunto parece que, en sistemas tan distintos como el continental y el angloamericano, la práctica tiene más puntos en común que divergentes, como se verá que ocurre con la defensa que seguidamente se aborda. $^{39}$

\subsection{Breve evolución de la insanity defense}

La insanity defense, por su amplitud y carácter eminentemente jurídico, ha permitido cubrir en los EUA todos los supuestos en los que existe un mal funcionamiento intelectual $^{40}$, aunque al igual que en la mayoría de países europeos de tradición civilista con las alusiones a las anomalías o alteraciones psíquicas, las disfunciones afectivas son difícilmente reconocibles en su sistema, teniendo en cuenta, además, que la regla concreta que dota de contenido a la misma varía en cada estado. ${ }^{41}$ En realidad, también en los países de common law, desde la primera absolución por insanity, los tribunales y los legisladores se han esforzado de forma infructífera en desarrollar una definición de esta confusa categoría, que puede surtir diferentes efectos en un proceso criminal dependiendo del momento en que la misma se presente. ${ }^{42}$

Han sido cuatro pruebas las que han gozado de apoyo en la historia legal estadounidense: la regla M'Naghten, la prueba del impulso irresistible, la regla Durham y la definición del Model Penal Code (en adelante MPC); modalidades que se correlacionan con las fórmulas continentales respecto del contenido que la inimputabilidad ha ido adquiriendo a lo largo de su evolución. Concretamente, la primera consideración de un trastorno mental con efectos en la responsabilidad en el common law se encuentra en el pronunciamiento de la Cámara de los Lores en el famoso caso M'Naghten ${ }^{43}$ en el Reino Unido, convirtiéndose rápidamente esta doctrina en la norma generalmente aceptada. A pesar de ello, la crítica a esta regla ha sido interminable, fundamentalmente porque la misma acoge únicamente defectos cognitivos, por lo que su prueba científica ha quedado obsoleta, sobre todo teniendo en cuenta que las teorías psiquiátricas modernas sugieren que los trastornos mentales afectan en muchas ocasiones a la capacidad afectiva,

\footnotetext{
${ }^{39}$ Interesante es, en este sentido, el análisis efectuado por BUSATO sobre la pertinencia de acercamiento entre ambos sistemas a través de la concepción significativa de la acción en las versiones de Vives y Fletcher. Al respecto, consultar: BUSATO (2007), passim.

${ }^{40}$ En este sentido, conviene destacar que, aunque no se exige que los trastornos deriven de lo que puede denominarse técnicamente como enfermedad mental, sí se exige que sean producto de una enfermedad, entendiendo como tal que la causa sea endógena y no externa.

${ }^{41}$ SCHUG y FRADELLA (2015), pp. 474-475.

${ }^{42}$ Concretamente, cuando se presenta en el momento de la comisión del delito se está ante la insanity defense para la generalidad de delitos o la diminished responsability para el caso de homicidio. Esta defensa, que pretende afirmar que en el momento de la comisión del delito el agente se encontraba incapacitado por una deficiencia mental, como ocurre en el ámbito continental, no descansa simplemente en la opinión médica pertinente, sino que se ha convertido en un concepto prácticamente legal acuñado por el common law y contenido en las reglas M'Naghten. Referencias: PIÑA ROCHEFORT (2002), p. 119, nota 263; Kansas v. Bethel, 66 P.3d 840 (Kan. 2003); Utah v. Mace, 921 P.2d 1372 (Utah 1996); Montreal v. Cowan, 861 P.2d 884 (Mont. 1993); Idaho v. Winn, 828 P.2d 879 (Idaho 1992); Finger v. Nevada, 27 P.3d 66 (Nev. 2001).

${ }^{43}$ Respecto del proceso de positivización de las famosas reglas M'Naghten, hay que remontarse al año 1843, cuando Daniel M'Naghten, acusado de matar por error al secretario de su verdadero objetivo, Sir Speel, fue absuelto por insanity del cargo de homicidio. Estas circunstancias motivaron un importante debate social y político que llegó hasta la Cámara de los Lores, los cuales emitieron a los jueces una serie de preguntas cuyas respuestas se transformaron, posteriormente, en las reglas que llevan su nombre. PIÑA ROCHEFORT (2002), p. 119, nota 263.
} 


\section{Polít. Crim. Vol. 15, № 29 (Julio 2020), Art. 8, pp. 230-258 \\ [http://politcrim.com/wp-content/uploads/2020/07/Vol15N29A8.pdf]}

quedando intactas las clásicas habilidades cognitivas. ${ }^{44}$ En consecuencia, muchos tribunales ampliaron su ámbito de aplicación mediante la inclusión del llamado "impulso irresistible" 45 , si bien, al igual que ocurrió con M'Naghten, la prueba extrema (dado que es psicológicamente ingenuo exigir la incapacidad total de control), junto con su inadecuada denominación, provocaron su rápido abandono. En este devenir apareció, así pues, la biologicista regla Durham ${ }^{46}$, la cual supuso un cambio drástico en la jurisprudencia de la insanity, aunque de la misma manera que la continental fórmula biologicista de las eximentes, fue rápidamente anulada por el exceso de autoridad de los expertos en salud mental en la determinación de la responsabilidad penal ${ }^{47}$ en base a la regla del MPC del American Law Institute (en adelante ALI), ${ }^{48}$ regla que gozó de una rápida aceptación general por la eclecticidad en su contenido. Según la misma, regulada en la sección $\$ 4.01$ del MPC, una persona no es responsable de su conducta si, en el momento de su comisión, como resultado de una enfermedad o deficiencia mental, le falta la capacidad sustancial para apreciar la ilicitud de aquella, o conformar su conducta de acuerdo a las exigencias de la ley. Pero, aunque se trata esta de una disposición relativamente amplia, los tribunales la han interpretado tradicionalmente de un modo restrictivo para excluir, entre otros, a los trastornos psicopáticos, a pesar de que, como MORSE destaca, de las palabras de esta sección no se deriva tal conclusión necesariamente. ${ }^{49}$

Esta regla fue adoptada con variaciones en todos los tribunales federales de circuito de apelaciones (a excepción de uno de ellos), y, aunque con matices, parece una formulación relativamente adecuada, dado que permite un equilibrio propicio entre la clásica cognición y la volición. No obstante, el proceso racional en el que esta defensa descansa (al igual que las eximentes de anomalías o alteraciones psíquicas continentales), sería una conjugación de elementos cognitivos y afectivos, como los estudios neurocientíficos refieren $;{ }^{50}$ componentes que se deberían considerar en la valoración de esta categoría y

\footnotetext{
${ }^{44}$ De hecho, desde la Criminología se denuncia el empleo excesivamente restringido de la prueba, junto con el controvertido uso de la palabra conocer que se utiliza. Asimismo, es objetable su carácter extremo, puesto que no reconoce grados de incapacidad (las personas aparecen como capaces o incapaces de forma absoluta), y limita también indebidamente el testimonio de expertos. DRESSLER (1992), p. 289.

${ }^{45}$ Con el fin de ampliar el alcance de la regla M'Naghten, algunos estados y ciertos tribunales federales formularon una tercera clavija para abarcar enfermedades mentales que afectaban exclusivamente a la capacidad volitiva, si bien el lenguaje preciso de la prueba variaba según la jurisdicción, aludiéndose a un impulso irresistible e incontrolable en unos, a la pérdida del poder de elección entre el bien y el mal, o inclusive la ausencia de libertad de voluntad; formulaciones desfasadas a la luz de los nuevos estudios neurobiológicos y que explican su desuso.

${ }^{46}$ De acuerdo con la Regla Durham, un acusado no puede ser declarado culpable de un delito si el acto en cuestión fue el resultado de una enfermedad o deficiencia mental en el momento del incidente. Aunque casi la totalidad de los tribunales y cortes federales rechazaron esta fórmula por ser demasiado amplia, en el estado de New Hampshire todavía se utiliza, si bien los tribunales han reducido su interpretación en un esfuerzo por limitarla en los casos más graves. Referencias: Durham v. United States (214 F. 2d862)

${ }^{47}$ A partir, concretamente, del famoso caso United States v. Brawner, en el que el tribunal declaró que el estado mental, aunque no es suficiente para exonerar, puede ser relevante para el elemento de intencionalidad específico requerido. De hecho, la sentencia se acoge a la definición de enfermedad o deficiencia mental del caso McDonald v. United States, basada en la regla del ALI, al entender que tal definición incluye cualquier condición anormal de la mente que afecte sustancialmente a los procesos mentales o emocionales y deteriore en gran medida el control comportamental. Referencias: Mc Donald $v$. United States. 114 U.S.App. DCen 124, 312F.2d en 851; United States v. Brawner (471F. 2d969).

${ }^{48}$ Realmente, la prueba del $§ 4.01$ del MPC es una versión revisada de M’Naghten y la prueba de impulso irresistible.

${ }^{49}$ MORSE (2001), p. 930.

${ }^{50}$ GRAY (2004), p. 48.
} 
no la clásica voluntad, cada vez más desacreditada en tales investigaciones. Con independencia de estas precisiones de contenido, la tendencia a favor de la regla del MPC fue imparable hasta que se produjo el intento de asesinato del presidente Ronald Reagan, que dio paso a un gran descontento ciudadano por la absolución del acusado John Hinckley precisamente en base a esta interpretación de la insanity defense. A partir de este momento, los tribunales comenzaron a reconsiderar su apoyo a esta amplia regla, ${ }^{51} \mathrm{y}$ California, que había adoptado la prueba del MPC en el año 1978, dejó de utilizarla en 1982, volviendo a M'Naghten. En la misma dirección, el congreso aprobó una ley de retroceso que definía la insanity en términos en gran parte basados en M'Naghten.

Ciertamente, el caso Hinckley puede ser considerado como un precedente en la utilización de la neuroimagen, al aportar la defensa del acusado una TAC en la que se advertían las huellas cerebrales de una esquizofrenia. Y, precisamente como respuesta a la presión pública en este famoso caso, el congreso de los EUA promulgó la Ley de Reforma de la Insanity defense de 1984 (18 USCA§17) que, como se avanzó, endureció el estándar para la aplicación de esta defensa en casos federales, teniendo el acusado a partir de entonces la carga de la prueba, por lo que debe demostrar que, como resultado de una enfermedad o defecto mental grave, no fue capaz de apreciar la naturaleza y la calidad o ilicitud de sus actos. ${ }^{52}$ Con todo, si bien el futuro de la insanity defense no se puede predecir, no parece que lo más apropiado sea volver a unas reglas como las M'Naghten, desarrolladas en un momento donde el conocimiento médico sobre el funcionamiento de la mente era excesivamente limitado.

Ahora bien, aunque en la mayoría de estados se apuesta por una aparente fórmula mixta, la concreta interpretación que de la misma se realiza determina unas consecuencias verdaderamente dispares. En general, se puede decir que los resultados en los EUA son más restrictivos que, por ejemplo, en España, dado que la diminished responsability a la que correspondería en el sistema español la semiimputabilidad, como se ha analizado, no es una defensa general, sin olvidar que la tendencia actualmente imperante es reacia a apreciar los trastornos afectivos en esta fórmula, los cuales sirven, como mucho, para esquivar la cadena perpetua o la pena capital. ${ }^{53}$ De hecho, la parcialidad de la respuesta del sistema estadounidense ha provocado que algunas jurisdicciones establezcan el veredicto de "culpable pero mentalmente enfermo" (Guilty but mentally ill), ${ }^{54}$ según el cual, aunque el acusado sufriría una enfermedad mental, tendría la capacidad suficiente

\footnotetext{
${ }^{51}$ SHIPLEY y ARRIGO (2012), pp. 25 y ss.

${ }^{52}$ En cuanto a la validez de la ley, cabe destacar que varios tribunales han dictaminado su compatibilidad con las exigencias constitucionales del debido proceso (Entre otros: United States v. Amos (1986, CA8Mo) 803 F2d 419; United States v. Byrd (1987, CA8Mo) 834 F2d 145; United States v. Freeman (1986, CA11Ala) 804 F2d 1574, 22 de las Reglas de la Fed Evid Serv 154, United States v. Hill (1990, NDGa) 750 F Supl 524), y entienden que no sería inconstitucional al exigir el requisito del quantum de la prueba en vez de simplemente una preponderancia de la evidencia (Pueden ser consultados, entre otros: United States v. Pryor (1992, CA1Me) 960 F 2d1; United States v. Amos (1986, CA8Mo) 803F2d419; Leland v. Oregon 343 790, 96LEd1302, 72CtS1002 (1952)). Asimismo, aunque en contra de la aplicación de esta regla se ha alegado en ocasiones la existencia de un castigo cruel o inusual, el mismo se ha negado debido a la naturaleza incierta de la teoría psiquiátrica en esta área (United States v. Freeman, 804 F.2d 1574 -11th Cir. 1986- ), de igual manera que se ha rechazado que la defensa fuera aplicable en procedimientos de revocación de la libertad condicional. Referencias: PIÑA ROCHEFORT (2002), p. 13 y ss.

$53 \S 48$. Distinction between legal insanity and mental illness, 21 American Jurisprudence Criminal Law, Second Edition. Database updated August 2014.

${ }^{54}$ Cuestionan esta categoría, entre otros: MELTON (2011), passim.
} 


\section{Polít. Crim. Vol. 15, № 29 (Julio 2020), Art. 8, pp. 230-258 \\ [http://politcrim.com/wp-content/uploads/2020/07/Vol15N29A8.pdf]}

para comprender la ilicitud de su conducta y la diferencia entre el bien y el mal ${ }^{55}$ un veredicto, en palabras de Morse ${ }^{56}$ fraudulento. Además, resulta verdaderamente sorprendentemente que algunas jurisdicciones hayan abolido incluso esta defensa en casos de asesinato en base a que los acusados no tendrían un derecho fundamental a la misma bajo la Constitución de los EUA. ${ }^{57}$

Al margen de lo apuntado, es en la insanity defense donde muchos creen que las técnicas de neuroimagen deberían tener una mayor repercusión, más allá de la fase de sentencia. Pero, aunque la neuroimagen ya se ha introducido en el proceso penal, los tribunales estadounidenses continúan valorando la mejor manera de aplicar las normas probatorias a las nuevas formas de evidencia neurocientífica, ${ }^{58}$ donde parece que lo más conveniente sean aplicaciones cuidadosas y específicas según el contexto. En definitiva, como en múltiples estudios se advierte, los métodos, los objetivos y las normas de prueba son diferentes para la Neurociencia y el Derecho, ${ }^{59}$ por lo que las autoridades pueden usar diferentes estándares en función de los específicos intereses en juego, ${ }^{60}$ de modo que, con independencia de las deficiencias de estas técnicas ${ }^{61}$, tal vez la clave para su admisión sea la fase concreta de aportación y su relación con el comportamiento enjuiciado; relación que está empezando a demostrarse ante los debatidos trastornos de la personalidad, con lo que la fase de culpabilidad, pese a no tener actualmente un buen pronóstico, se erige, en teoría, como un momento oportuno para aportar los datos neurocognitivos.

Esto es, desde el ámbito jurídico nos deberíamos centrar en determinar las competencias para la realización de estas pruebas y los procedimientos, reglas y precauciones a tomar, más aún si se tiene en cuenta que las pruebas que hoy en día son usadas en el terreno forense al respecto tienen inclusive una fiabilidad significativamente menor a estas técnicas de neuroimagen, las cuales permitirían fortalecer las decisiones en dichos casos particulares, al aumentar su fiabilidad, aunque con valor meramente probatorio. Concretamente, los estudios citados han empezado a detectar que determinados esquemas emocionales pueden convertirse en una forma de psicopatología, y demuestran, a modo meramente ejemplificativo, la relación entre algunos trastornos de la personalidad, especialmente la psicopatía, y una desregulación emocional con claras repercusiones en la capacidad racional, ${ }^{62}$ la cual integra elementos no únicamente cognitivos, sino también afectivos, ${ }^{63}$ por lo que el sistema de justicia debería empezar a prestar más atención a estos trastornos. Y, en esta línea, la neuropsicología forense puede convertirse en una importante herramienta auxiliar en el Derecho Penal para la evaluación forense de los déficits cognitivos y afectivos que tienen los reos que presentan un trastorno mental.

\footnotetext{
${ }^{55}$ Se pueden consultar, entre otras: Ervin v. State, 531 N.E.2d 186 (Ind. 1988); People v. Ramsey, 422 Mich. 500, 375 N.W.2d 297, 71 A.L.R. 4th 661 (1985).

${ }^{56}$ MORSE, "Avoiding", cit. nota n ${ }^{\circ} 33$, p. 934.

${ }^{57}$ Am. Jur. 2d, Criminal Law $§ 46$.

${ }^{58} \mathrm{La}$ aplicación de las nuevas técnicas ha creado muchos problemas prácticos para los jueces estadounidenses, sobre todo respecto a su admisibilidad, interpretación o impacto en los miembros del jurado. Se han hecho eco de estas controversias, entre otros: MORIARTY (2008), p. 29; PETTIT (2007), p. 319.

${ }^{59}$ JONES (2004), p. 1697; SAPOLSKY (2004), pp. 1787-1788; SCHAUER (2010), p. 1191.

${ }^{60}$ FAIGMAN (2002). pp. 339-340.

${ }^{61}$ Un análisis de las deficiencias de estas técnicas, entre muchos otros: BASKIN (2007), pp. 239-244; GAZZANIGA p. 412; LOGOTHETIS (2008), p. 869; MOBBS (2007), p. 693; POLDRACK (2008), p. 409; RACINE et al. (2005), p. 159; TROUT (2008), p. 281.

${ }^{62}$ ABBOTT (2007), passim.

${ }^{63}$ Entre muchos otros: BISHOP et al. (2007); PESSOA et al. (2002); PHELPS (2006), passim.
} 


\section{Neuroimagen forense en Estados Unidos}

\subsection{Recurso in crescendo en el proceso penal}

La discusión acerca de la introducción de la ciencia en los tribunales ha sido más fructífera en los EUA que en cualquier otro país, convirtiéndose los casos Frye ${ }^{64}$ o Daubert ${ }^{65}$ en referentes mundiales hoy en día, dado que, con anterioridad a estos, los jueces analizaban la evidencia científica como cualquier otro tipo de prueba, sin atender por tanto a sus particularidades. Por el momento, la evidencia neurocientífica ha sido introducida en el proceso penal estadounidense mediante el testimonio de expertos, como también en forma de gráficos de las imágenes obtenidas a través de métodos como la RMf o la electroencefalografía (en adelante, "EEG"), si bien, teniendo en cuenta el diseño institucional vigente en este sistema, su admisibilidad es altamente contextual incluso en el sistema federal. Esta divergencia se produce al contar con diferentes jurisdicciones superpuestas (local, estatal y federal ${ }^{66}$ ) con reglas de admisión propias ${ }^{67}$, lo que comporta aplicaciones verdaderamente dispares, siendo en todo caso más fácil su admisión en la última fase de sentencia, ${ }^{68}$ pues cuando se discute la culpabilidad normalmente este tipo de pruebas son rechazadas. ${ }^{69}$

De todos modos, como Denno ${ }^{70}$ destaca, las normas articuladas por la CS en el caso Strickland v. Washington ${ }^{71}$ se están empezando a aplicar en el contexto neurocientífico, las cuales establecen que los abogados no solo deben investigar y utilizar todas aquellas pruebas disponibles cuando sea idóneo para la minoración de responsabilidad de sus representados, sino que también se penaliza rechazar su uso. En efecto, en Frierson v. Woodford, ${ }^{72}$ el acusado recurrió al amparo federal al no presentar su abogado pruebas

\footnotetext{
${ }^{64}$ En este famoso caso, los abogados de Frye, acusado de asesinato, solicitaron al juez que se le practicase la prueba de la verdad basada en la presión arterial sistólica, un antecesor de los modernos detectores de mentiras. No obstante, el juez inadmitió la prueba, de la misma manera que la Corte de Apelaciones, al entender que, para admitir una prueba científica, la misma debía estar suficientemente establecida como para haber conseguido una aceptación general en el campo particular al cual pertenece. Al respecto, consultar: Frye v. United States, 293 F. 1013 (D.C. Cir. 1923).

${ }^{65}$ Concretamente, se trara de la demanda a una compañía farmacéutica (Merrell Dow Pharmaceuticals), por el uso de un fármaco, utilizado para evitar los mareos matinales durante el embarazo, que supuestamente producía en los fetos determinados defectos en el nacimiento. Si bien finalmente no se pudo demostrar científicamente la relación entre las malformaciones y el medicamento, este caso abrió la puerta del debate sobre la pseudociencia y los protocolos experimentales no suficientemente avalados por la comunidad científica, como en epígrafes siguientes se detallará. Para más información, consultar: Daubert v. Merrell Dow Pharmaceuticals, Inc. 509 U.S. 579 (1993); LYNCH y McNALLY (1999), pp. 183-196.

${ }^{66}$ Brevemente, en los EUA tanto el gobierno federal como los diferentes estados están facultados para procesar delitos penales, dependiendo las reglas para que un determinado delito sea procesado por el Estado o por el gobierno federal de múltiples y complejos, si bien, en general, los estados procesan la mayoría de los delitos contra las personas, como asesinatos y agresiones. Referencias: ESPARZA LEIBAR et al. (2013), passim.

${ }^{67}$ BARKOW (2011), p. 519; STUNTZ (2008), p. 1969.

${ }^{68}$ RUSHING (1996), pp. 62-69.

${ }^{69}$ De hecho, en algunos casos se han rechazado pruebas que demostraban daños en los lóbulos frontales de los acusados (los cuales correlacionarían con comportamientos impulsivos), en base a que tales anormalidades no impedirían diferenciar el bien y el mal; condición indispensable según la regla M'Naghten seguida, como vimos, en la mayoría de estados, si bien, como Roth destaca, se detectan consideraciones morales latentes en tal determinación. Ver, ROTH (2012), p. 223; State v. Sopczak, No. 02-KA-235 (La. Ct. App. 2002).

${ }^{70}$ DENNO (2015), pp. 517 y ss.

${ }^{71}$ Strickland v. Washington, 466 U.S. 668 (1984).

${ }^{72}$ Frierson v. Woodford, 463 F.3d 982 (9th Cir. 2006).
} 


\section{Polít. Crim. Vol. 15, № 29 (Julio 2020), Art. 8, pp. 230-258 \\ [http://politcrim.com/wp-content/uploads/2020/07/Vol15N29A8.pdf]}

atenuantes respecto de varios trastornos traumáticos que el mismo padecía. En igual sentido, en James v. Ryan, ${ }^{73}$ el acusado, condenado a muerte por asesinato, apeló la negativa de su abogado a examinar la apreciación de diferentes circunstancias atenuantes, entre ellas un trastorno mental o su historia de abuso crónico de drogas, estimando finalmente el tribunal una asistencia letrada inefectiva.

Para iniciar el estudio de los primeros pasos de la neuroimagen como medio de prueba de deficiencias psíquicas en el proceso penal, conviene detenerse en el caso pionero Weinstein $^{74}$, en el que la defensa pretendió utilizar estas pruebas en un juicio donde se discutía el estrangulamiento por parte del acusado de su esposa, además de manipular posteriormente la escena del crimen para simular un suicidio. Concretamente, para fundamentar la apreciación de la insanity defense se aportó una prueba de resonancia magnética (en adelante, "RM") que detectó en el cerebro de Weinstein un gran quiste en un revestimiento protector que cubre el tejido cerebral, además de una tomografía que reveló que las áreas de tejido cerebral que se habían comprimido por el llamado quiste aracnoideo no metabolizaban la glucosa en la tasa esperada, por lo que su funcionamiento cerebral, dependiente de esta sustancia para sobrevivir, no sería óptimo. ${ }^{75}$ Pero, a pesar de que esta prueba se admitió, el jurado entendió que la misma no era determinante al respecto, dado que era discutible la relación de causalidad entre el quiste congénito que el investigado padecía y un único acto de violencia. ${ }^{76}$ Como expresamente se destacó, la sensibilidad y especificidad del hipometabolismo frontotemporal para la impulsividad y la violencia era desconocida, por lo que la defensa no podía ser apreciada; veinte años después, es discutible si la decisión hubiese sido distinta.

Sin embargo, hoy en día la controversia sobre la admisibilidad de las pruebas neurocientíficas continúa, difiriendo la misma, como ya se ha apuntado, de la fase del procedimiento en la que se alegue. Ahora bien, pese a las reticencias que en principio su introducción planteó, en el año 2006 se encontraban ya 130 opiniones legales que involucraban técnicas como la Tomografía por Emisión de Positrones (en adelante, "PET") o la Tomografía Computarizada de Emisión Monofotónica (en adelante, "SPECT") 77 , las cuales se han llegado a admitir inclusive en la fase previa de determinación de la competencia general para ser juzgado; un número que, como seguidamente se abordará, sigue en aumento. ${ }^{78}$

\footnotetext{
73 James v. Ryan, 679 F.3d 780, 784-85 (9th Cir. 2012), vacated, 133 S. Ct. 1579 (2013).

${ }^{74}$ People v. Weinstein, 591 N.Y.S.2d 715 (N.Y. Sup. Ct. 1992).

${ }^{75}$ La PET que se realizó en este caso mide la función cerebral mediante el consumo de glucosa del cerebro, su fuente principal de energía. Por ello, una metabolización anormal de la glucosa puede revelar una anomalía en el funcionamiento cerebral.

${ }^{76}$ En cualquier caso, conviene remarcar que, aunque Weinstein no tenía antecedentes por comportamiento violento, había sufrido una convulsión de origen desconocido en la década de 1940.

${ }^{77}$ FEIGENSON (2006), pp. 233-255.

78 De hecho, diferentes estudios llevados a cabo por el Proyecto Mac Arthur ponen de relieve que la evidencia neurocientífica ha sido introducida en diferentes procedimientos en California, poniéndose en contacto los investigadores con abogados y defensores públicos en todos los condados para determinar cómo los tribunales confían en tal información. Para más información, consultar: KOLLA (2012), p. 152.
} 


\subsection{Viabilidad de la aportación según la fase del procedimiento}

\subsubsection{Determinación de la competencia}

Precisamente, uno de los incipientes procedimientos en los que las técnicas de neuroimagen fueron admitidas en esta etapa previa de determinación de la competencia, que es tratada como una cuestión de derecho, y por ello determinada por el juez de la causa y no por un jurado, lo protagoniza el caso United States v. Kasim ${ }^{79}$ (con la utilización de las técnicas de RM, PET y $\mathrm{EEG}^{80}$ ), junto con la causa California v. Miguel Carrizale $^{81}$, en la que, aunque finalmente el tribunal encontró al investigado competente para juicio, se permitió una PET al entender que esta técnica, aceptada en la comunidad científica y en el ámbito forense, constituía una prueba válida. No obstante, el joven pudo finalmente sortear la pena de muerte al presentarse nuevamente esta prueba, que evidenciaba una severa lesión cerebral, en la fase de sentencia, donde sí fue tomada en consideración.

Es interesante recordar que la Corte Suprema ha articulado respecto de la determinación de la competencia para ser sometido a juicio una excepción específica al famoso estándar cognitivo Dusky, establecido en el caso Godinez v. Morán: ${ }^{82}$ en Indiana v. Edwards, ${ }^{83}$ la Corte entendió que un estado puede incrementar el estándar de competencia, y afirmó que (aspecto ciertamente preocupante debido a su colisión con el principio de culpabilidad), mientras la cláusula del debido proceso de la XIV Enmienda permite a un acusado incompetente no ser juzgado, la Constitución no obligaría a los estados a reconocer los trastornos mentales como defensa, sin olvidar, asimismo, que cada estado puede limitar qué tipo de enfermedad o defecto mental puede dar lugar a una exitosa defensa ${ }^{84}$. En todo caso, lo cierto es que la alegación de trastornos en esta fase previa de determinación de la competencia para ser juzgado es verdaderamente peligrosa para el procesado, puesto que el internamiento es en ocasiones de por vida, y conforma una zona descuidada y mal definida por la ley, que únicamente especifica que el acusado tiene el derecho constitucional a no ser juzgado, condenado, sentenciado o ejecutado mientras sea incompetente. ${ }^{85}$ Además, en la misma la neuroimagen cuenta, a la vista de la práctica existente, con muy pocas posibilidades de ser admitida; sirva, como ejemplo, el caso United States v. Gigante, ${ }^{86}$ en el que, aunque una prueba SPET mostró que el acusado padecía una disfunción cerebral orgánica, y a pesar de que el propio tribunal reconoció que la exploración era de una excelente calidad técnica, se entendió que la misma contaba con una serie de dificultades de interpretación que impedían tenerla en consideración, pues el acusado había estado tomando ciertos medicamentos psicotrópicos que podrían haber distorsionado los resultados.

\subsubsection{Fase de culpabilidad}

\footnotetext{
${ }^{79}$ United States v. Dr. Jihad Kasim. Cause No. 2:07 CR 56. (N.D. Ind. Nov 03, 2008).

${ }^{80}$ También fue admitida esta tecnología en el caso de McMurtrey, un caso de pena capital. Al respecto, consultar: McMurtrey v. Ryan, 539 F.3d 1112 (9th Cir. 2008).

${ }^{81}$ California v. Miguel Carrizalez, (2011) (No. VCF 169926C).

${ }^{82}$ Godinez v. Moran, 509 U.S. 389, 404 (1993).

${ }^{83}$ Indiana v. Edwards, 554 U.S. 164 (2008).

${ }^{84} \mathrm{El}$ fundamento jurídico de esta afirmación, y la creciente importancia que se le concede en las audiencias de competencia derivan de la casuística y de los diferentes casos en los que los expertos han validado estas técnicas. NUGENT (2012), pp. 275-302.

${ }^{85}$ MARONEY (2006), p. 1378.

${ }^{86}$ United States v. Gigante, 982 F.Supp. 140, 159 (1997).
} 
Donde se entiende que estas pruebas deberían adquirir especial importancia es en la fase de culpabilidad, si bien los férreos requisitos de esta etapa impedirán, como seguidamente se detallará, una defensa exitosa. Concretamente, como avanzamos en puntos anteriores, existen dos momentos para su introducción: para negar el mens rea o en apoyo de la insanity defense. Respecto al mens rea, el elemento depende del estado mental del procesado en el momento del delito, y pese a que como regla general hay una presunción de que el acusado estaba pensando de tal modo, podrían aportarse los datos derivados de estas pruebas de neuroimagen en un intento de demostrar que el procesado carecía de las capacidades cognitivas necesarias para formar la intención mental específica. A pesar de ello, la neuroimagen no revela estados mentales ni intenciones, por lo que en esta fase lo más apropiado sería una defensa afirmativa de insanity, rigiéndose la admisibilidad de estas pruebas por las normas que se utilizan para evaluar las pruebas científicas generales. ${ }^{87}$

Interesa recordar en este punto que el caso Semrau se erigió en el año 2010 como el primer proceso en el que se planteó la admisibilidad de la RMf en la etapa de culpabilidad, y pese a que en este pionero caso de detección de mentiras la prueba neurocientífica no fue admitida, el juez dejó abierta la posibilidad para el futuro, ${ }^{88}$ analizando los cuatro requisitos exigidos por Daubert para la admisibilidad de un medio probatorio: la prueba de la técnica, la revisión por pares, la tasa de error y la aceptación por la comunidad científica. Sin embargo, aunque lo cierto es que el caso Daubert es un ejemplo de cómo los tribunales estadounidenses podrían aplicar las normas probatorias generales, ello no implica, necesariamente, que las mismas se apliquen del mismo modo en todos los casos. De hecho, a nivel estatal, pese a que algunos estados han adoptado el enfoque Daubert, otros todavía dependen de la prueba de aceptación general Frye, sin olvidar aquellos que han mezclado ambos criterios. No fue así, en todo caso, en el procedimiento United States v. Montgomery, ${ }^{89}$ en el que, un año después de la causa Semrau, se excluyó igualmente una prueba neurocientífica, en este caso una PET, en base a estos mismos requisitos de admisibilidad.

Con independencia de lo enunciado, en aquellos supuestos donde se discuten trastornos de la personalidad, la neuroimagen está empezando a ser alegada para demostrar déficits cerebrales en el control de los comportamientos violentos o impulsivos, sobre todo porque, aunque la mayoría de los estados excluyen la intoxicación voluntaria de la insanity defense (exclusión declarada permisible por la $\mathrm{CS}^{90}$ ), hay excepciones cuando tal intoxicación es debida a un defecto mental crónico. ${ }^{91} \mathrm{Y}$, si bien ello no se traduce en un mandato constitucional como tal, la jurisprudencia de la corte aboga por la discreción judicial para considerar la información más completa posible en relación con el acusado, de modo que una prohibición general del uso de pruebas de neuroimagen sería constitucionalmente sospechosa, especialmente en aquellos casos en los que se discutiera la pena capital. Ahora bien, como en las conclusiones se detallará, estos problemas podrían ser solucionados con una reforma de la diminished responsability como defensa

\footnotetext{
${ }^{87}$ En el sistema federal, los tribunales aplican la Regla Federal de la Evidencia 702 (Testimony by Expert Witnesses) y la Regla Federal de Evidencia 403 (Excluding Relevant Evidence for Prejudice, Confusion, Waste of Time, or Other Reasons).

${ }^{88}$ JONES y SHEN (2004), p. 861.

${ }^{89}$ United States v. Montgomery, 635 F.3d 1074 (8th Cir. 2011).

${ }^{90}$ FEIX y WOLBER (2007), pp. 172-182.

${ }^{91}$ EDERSHEIM et al. (2012), p. 187.
} 
general, en línea con la propuesta de Morse, teniendo en cuenta que la regla que dota de contenido a la insanity defense, como vimos en el apartado anterior, es interpretada de forma restrictiva para excluir precisamente trastornos que afectan a la esfera afectiva, como los de la personalidad.

\subsubsection{Fase de sentencia}

Como se ha adelantado, donde más acogida han tenido las pruebas de neuroimagen ha sido en la fase de sentencia, especialmente cuando se discute la pena capital, ${ }^{92}$ tal vez debido a que en la misma son reconocidos como factores atenuantes todo tipo de datos, además de no requerir la prueba adicional dirigida a indicar que los mismos, como por ejemplo el abuso infantil, la falta de educación o la pobreza, afectaron directamente a la mente del acusado y, por tanto, a la culpabilidad. En contraste con la insanity defense, en las pruebas de mitigación no hay ningún requisito adicional, dado que únicamente se han de cumplir las normas de relevancia y fiabilidad (que, en todo caso, si no se superan, pueden fundamentar su exclusión ${ }^{93}$ ). Pues bien, aunque la fase de sentencia de un caso con pena capital es una de las etapas más difíciles para los abogados, sobre todo en el caso de acusados con psicopatía, ${ }^{94}$ en los últimos años los avances en las técnicas de neuroimagen han permitido identificar una amplia gama de anormalidades cerebrales que pueden ayudar a la mitigación ${ }^{95}$. De esta manera, en Lockett v. Ohio, ${ }^{96}$ se estableció que los condenados por un delito con pena capital tienen el derecho a presentar todo tipo de pruebas para evitar esta pena, y, en Tennard v. Dretke, ${ }^{97}$ la CS declaró que cualquier deterioro cognitivo o neuropsicológico podía ser considerado como un factor atenuante en estos supuestos; y precisamente las imágenes funcionales del cerebro son admitidas frecuentemente en estos casos.

Uno de los primeros procesos en los que las técnicas de neuroimagen fueron admitidas en esta fase fue el famoso caso Dugan. La defensa de Brian Dugan, sentenciado a muerte por el asesinato de dos niñas y una joven, aportó una RMf verdaderamente similar a las exploraciones cerebrales de los sujetos diagnosticados con psicopatía. ${ }^{98} \mathrm{Y}$, aunque el juez no permitió mostrar a los miembros del jurado las imágenes cerebrales obtenidas, el neurocientífico Kiehl, experto en estos trastornos y al que se le encomendó la realización de estas pruebas, testificó en el juicio informando del déficit emocional propio de los sujetos con trastornos psicopáticos, como parecía que padecía el acusado, y para ello mostró diferentes tipos de gráficos en un intento de convencer a los miembros del jurado de la relevancia que los trastornos emocionales deberían tener en la responsabilidad jurídica. Pero, si bien finalmente los miembros del jurado desatendieron estas

\footnotetext{
${ }^{92}$ La jurisprudencia de la CS de los EUA sobre la pena capital tiene sus raíces en la Octava Enmienda, que prohíbe los castigos crueles e inusuales, considerando como tales su imposición a personas con retraso mental o menores de 18 años. De tal manera, en los estados en los que rige la pena de muerte, la CS requiere que se permita al acusado presentar cualquier prueba que le permita evitarla, motivo por el cual cualquier defecto del condenado, ya sea cognitivo, volitivo o emocional, debe ser admitido.

${ }^{93}$ United States v. Mezvinsky, 206 F. Supp. 2d 661 (E.D. Pa. 2002).

${ }^{94}$ BARTH (2007), p. 510; FOX et al. (2012), p. 1-26.

${ }^{95}$ WALKER (2013), p. 1779.

${ }^{96}$ Lockett v. Ohio, 438 U.S. 586 (1978).

${ }^{97}$ Tennard v. Dretke, 542 U.S. 274 (2004).

${ }^{98}$ Para más información, consultar: HUGHES (2010), pp. 340-342.
} 


\section{Polít. Crim. Vol. 15, No 29 (Julio 2020), Art. 8, pp. 230-258 \\ [http://politcrim.com/wp-content/uploads/2020/07/Vol15N29A8.pdf]}

explicaciones, ${ }^{99}$ lo cierto es que el mismo comportó que se reabriera el debate sobre qué es aquello que se debe valorar en la responsabilidad penal.

En esta línea, el mismo derecho a presentar pruebas de neuroimagen se ha convertido en objeto de litigo. ${ }^{100}$ Concretamente, en el Estado de Florida el derecho a aportar tales pruebas (concretamente una PET), se configuró conforme al caso Hoskins, ${ }^{101}$ y el rápido incremento de este tipo de técnicas está conduciendo a que se pueda considerar como motivo de apelación negar la posibilidad de su presentación en casos de pena capital, pues si en estos procesos el abogado no presenta pruebas atenuantes para armar la defensa, se puede reclamar por asistencia letrada ineficaz, como ocurrió en el conocido caso Caro, ${ }^{102}$ o en el de Hernandez v. Martel, ${ }^{103}$ en el que un tribunal de California anuló una sentencia de muerte al no ser aportadas pruebas psiquiátricas o neurológicas. En igual sentido, en el caso State v. Marshall, ${ }^{104}$ la CS de Washington estimó que el tribunal de primera instancia del estado cometió un abuso de discreción cuando no tuvo en cuenta diferentes pruebas ofrecidas por la defensa que demostraban la disfunción neurológica padecida por el acusado (concretamente, se trata de una RM, una EEG y una tomografía SPECT que ponían al descubierto distintas anormalidades cerebrales). De hecho, como concluyó la CS en el caso Smith v. Mullin ${ }^{105}$ (un supuesto en el que quedó probado que el acusado de matar a su esposa y a sus cuatro hijastros tenía graves anomalías en la esfera afectiva), la magnitud y repercusión penal de muchas de las anomalías en el funcionamiento cerebral que se detectan en algunos acusados podría ser concretada en el futuro mediante técnicas de neuroimagen ${ }^{106}$; un futuro cada vez más presente, dado que las mismas se están admitiendo en numerosos supuestos en los últimos años. ${ }^{107}$

En síntesis, los datos facilitados por la neuroimagen han sido presentados en esta fase de sentencia para demostrar diferentes tipos de trastornos: tanto lesiones traumáticoencefálicas, como se reconoció en el caso Rogers $v$. State,${ }^{108}$ como psicosis, ${ }^{109}$ trastornos de ansiedad, ${ }^{110}$ e inclusive para evidenciar anomalías en el lóbulo frontal similares a las que vimos en el pionero caso Dugan, que provocarían un deficiente control de los

\footnotetext{
${ }^{99}$ De todos modos, en el año 2011 el gobernador de Illinois conmutó la sentencia de muerte a Dugan, y firmó una ley que prohíbe la pena de muerte en el Estado. CBS Local (Mar. 9, 2011). Quinn Signs Death Penalty Ban, http://chicago.cbslocal.com/2011/03/09/quinn-expected-to-sign-death-penalty-bill/ [visitado el 25/06/2020].

${ }^{100}$ Ferrell v. State, 918 So. 2d 163, 175-76 (Fla. 2005); People v. Morgan (1999) 719 N.E.2d 681 (Ill. 1999).

${ }^{101}$ Hoskins v. State, 702 So. 2d 202, 209 (Fla. 1997).

${ }^{102}$ Caro v. Woodford, 280 F.3d 1247 (9th Cir.), cert. denied 536 U.S. 951 (2002)

${ }^{103}$ Hernandez v. Martel, 824 F.Supp. 2d 1025 (CD Cal. 2011)

104 State v. Marshall, 27 P.3d 192, 200 (Wa. 2001).

105 Smith v. Mullin, 379 F.3d 919, 939 (10th Cir. 2004).

${ }^{106}$ Interesa destacar en este punto uno de los procesos más famosos de la delincuencia juvenil: el caso Kinkel, referente a un joven que mató a diferentes compañeros en la cafetería de su centro educativo, y en el que las pruebas de neuroimagen sirvieron para justificar la insanity defense y evitar de este modo la pena capital del joven, como ocurrió posteriormente en el caso Coe. Para más información, consultar: State v. Kinkel, 184 Or. App. 277 (Or. Ct. App. 2002); Coe v. State, 17 S.W.3d 193, 243 (Tenn. 2000).

${ }^{107}$ CARTER (2006), pp. 1265-1287; SEIDEN (2004), pp. 395-342.

${ }^{108}$ Rogers v. State, 783 So.2d 980 (Fla. 2001). En igual sentido: State v. Reid, 213 S.W.3d 792 (Tenn. 2006).

${ }^{109}$ McNamara v. Borg 923 F.2d 862 (9th Cir. 1991).

${ }^{110}$ Stewart v. State, 37 So.3d 243, 249 (Fla. 2010); State v. Mercer, 672 S.E.2d 556 (S.C. 2009).
} 
impulsos ${ }^{111}$. Efectivamente, es creciente el número de juicios en los que se han aportado estas pruebas en base a anormalidades del lóbulo frontal (ejemplo de ello son los casos Mezvinsky, ${ }^{112}$ en el que se realizó una PET, o Ford, ${ }^{113}$ con una SPECT, en ambos casos rechazadas), lesiones cerebrales traumáticas (caso Protsman ${ }^{114}$ ) o, punto especialmente interesante, para fundamentar el padecimiento de trastornos de la personalidad. Como muestra de ello, en el caso Trapp v. Spencer, ${ }^{115}$ la defensa alegó que el procesado padecía un trastorno orgánico de la personalidad, y presentó como prueba una PET, si bien el tribunal denegó su introducción, teniendo en cuenta que la misma se le realizó veinte años después del asesinato por el que estaba siendo juzgado. Sin duda, se entiende que la inmediatez sería clave en este tipo de pruebas, especialmente en casos de anomalías funcionales, como ocurrió precisamente en el caso Yum. ${ }^{116}$ La defensa de este joven de 14 años, acusado de matar a su madre y hermana, aportó una tomografía SPECT para demostrar el padecimiento de un trastorno traumático, en la que se apreciaba una disminución de la actividad del lóbulo temporal izquierdo (mientras que en otras partes del cerebro se constató una hiperactividad). Sin embargo, el tribunal inadmitió esta prueba en base a que la doctrina especializada entendía que esta tecnología no era la más idónea para diagnosticar trastornos traumáticos, como en el caso en cuestión se argüía.

De todos modos, resulta paradójico que en ocasiones la acusación presente la evidencia de enfermedad mental como una circunstancia agravante, mientras que la defensa la utilice como una causa de mitigación. En esta línea, la CS ha alertado que algunas pruebas de neuroimagen podrían interpretarse como factores agravantes, particularmente cuando juegan supuestas predisposiciones biológicas y sociales a la delincuencia. En vista de ello, no se debería desconocer que, más allá de su uso pro reo, estas técnicas pueden servir para fundamentar tanto sentencias a pena de muerte (si bien la CS exige al menos un agravante legal para imponerla ${ }^{117}$ ), como también la peligrosidad o riesgo de reincidencia, al incorporarse los datos biológicos que estos estudios señalan en los nuevos instrumentos de predicción del riesgo actuariales, ${ }^{118}$ como ocurrió en el caso Barefoot v. Estelle. ${ }^{119} \mathrm{Y}$ esto es así porque, como se ha reiterado a lo largo del presente estudio, el uso de las

${ }^{111}$ Entre otras: Cooper v. State, 739 So.2d 82 (Fla, 1999); Hoskins v. State, 702 So.2d 202 (Fla. 1997); Hoskins v. State, 735 So.2d 1281 (Fla. 1999); People v. Morgan, 719 N.E.2d 681 (Ill. 1999); People v. Holt, 15 Cal.4th 619, 646 (Cal. 1997); Sexton v. State, 775 So.2d 923, 936 (Fla. 2000).

${ }^{112}$ La defensa de Edward Mezvinsky, acusado de múltiples cargos de fraude, entre ellos el bancario, alegó que el acusado padecía un trastorno bipolar, una encefalopatía tóxica y la lesión del lóbulo frontal, pero, aunque se quiso incluir entre estas pruebas una PET, el tribunal la inadmitió al entender que no tendría valor probatorio. Ver: United States v. Mezvinsky, 206 F.Supp.2d 661, 669-76 (ED Pa 2002).

113 Charles Ford, declarado culpable de asesinato en primer grado, apeló su condena en base a múltiples motivos, entre ellos su alcoholismo y una lesión cerebral que le produjo deficiencias en sus lóbulos frontal y temporal izquierdo, aportándose para ello una prueba SPECT. Sin embargo, esta evidencia fue rechazada por el tribunal al considerar que esta tecnología no contaba con la suficiente aceptación en la comunidad médica. Al respecto, consultar: People v. Ford, WL 236487 (Cal. Ct. App. 2005).

114 Eugene Protsman recurrió su condena por asesinato alegando que el tribunal de primera instancia cometió un error reversible al excluir el testimonio de un experto; experto que, mediante una PET, detectó una disminución de la actividad en su lóbulo frontal, compatible con una lesión cerebral traumática anterior, que le ocasionaría deterioros en el control de impulsos, la estabilidad emocional y el juicio, claramente relevantes en su culpabilidad. No obstante, como en los casos anteriores, el tribunal no admitió esta prueba. Al respecto, consultar: People v. Protsman 105 Cal.Rptr.2d 819.[47]. (2001).

115 Trapp v. Spencer, 470 F.3d 53 (1st Cir. 2007).

${ }_{116}$ People v. Yum, 3 Cal.Rptr.3d 855 (Cal Ct. App 2003).

117 Referencias: CANTERO y KLINE (2009), pp. 9-10; EDERSHEIM y BECK, (2005), pp. 519-522; FABIAN (2003), pp. 724-725; GARVEY (1998), pp. 1538-1576.

${ }^{118}$ Una aproximación a estos instrumentos en: MARTÍNEZ GARAY (2016), p. 15.

${ }^{119}$ Barefoot v. Estelle, 463 U.S. 880 (1983). 


\section{Polít. Crim. Vol. 15, № 29 (Julio 2020), Art. 8, pp. 230-258 \\ [http://politcrim.com/wp-content/uploads/2020/07/Vol15N29A8.pdf]}

pruebas de neuroimagen varía de acuerdo con las leyes particulares de cada jurisdicción, $\mathrm{y}$, aunque en delitos federales distintos de asesinato el congreso aprobó diferentes directrices que señalaban que en la determinación de la capacidad futura de peligrosidad debían ser consideradas no solo circunstancias agravantes, sino también atenuantes, a raíz del caso de United States v. Booker ${ }^{120}$ se estableció, de conformidad con la Sexta Enmienda, que tales directrices no eran obligatorias. En todo caso, afortunadamente los jurados conceden un peso mayor a las circunstancias atenuantes que a las agravantes.

\section{Conclusiones}

Tras el estudio efectuado se advierte que las técnicas de neuroimagen, al margen de sus usos más sensacionalistas, como el protagonizado por las pruebas de detección de mentiras, podrían ser utilizadas para un mejor diagnóstico y valoración de los trastornos mentales, siempre que fueran contrastadas sus inferencias. ${ }^{121}$ Por ello, Faigman, Monahan y Slobing, partiendo del problema "G2i”, esto es, del desafío inherente a todas las pruebas científicas de razonamiento de grupo y su extrapolación a los casos individuales que las ciencias aplicadas y el sistema judicial requiere, proponen una serie de directrices generales para guiar a los jueces en la valoración de esta información, entre ella la neurocientífica y posibilitar inferencias más coherentes en base a la distinción entre dos tipos de pruebas: la evidencia marco que describe las proposiciones científicas generales y las pruebas de diagnóstico que aplican las proposiciones generales a los casos individuales que serían las discutidas en este ámbito. ${ }^{122}$ En esta línea, la Fundación Mac Arthur ha publicado una guía que ofrece a los jueces información sobre estas cuestiones, y el Colegio Americano de Radiología ${ }^{123}$ y la Sociedad de Medicina Nuclear ${ }^{124}$ han elaborado manuales sobre los estándares aceptables de estas pruebas.

En realidad, los estudios neurocognitivos están empezando a mostrar las bases neurobiológicas de algunos de los trastornos más discutidos de la psicopatología forense, como por ejemplo la psicopatía ${ }^{125}$, en la que se encuentran comprometidas zonas cruciales en la toma de decisiones, el control del comportamiento y la regulación emocional, provocando ello la impulsividad o el deterioro del procesamiento emocional característico de estos sujetos ${ }^{126}$. Así pues, aunque estos avances deben ser acogidos con precaución ${ }^{127}$, especialmente porque todavía no se cuenta con una regulación al respecto, con el imparable avance de la Neurociencia las técnicas de neuroimagen tendrán cada vez una mayor repercusión en los procesos, ${ }^{128}$ erigiéndose como una herramienta auxiliar indispensable en la psicopatología forense que podría mejorar, sin duda alguna, las respuestas que se dispensan en los casos particulares.

De hecho, la neuroimagen puede mitigar las deficiencias de las pruebas psicológicas tradicionales e incrementar la confianza de un diagnóstico en el que no se debe olvidar su

\footnotetext{
${ }^{120}$ United States v. Booker, 543 U.S. 220 (2005).

${ }^{121}$ LOGOTHETIS (2008), p. 869.

${ }^{122}$ FAIGMAN et al. (2014), passim.

${ }^{123}$ COLEGIO AMERICANO DE RADIOLOGÍA. Guía Actualizada sobre Radiología.

${ }^{124}$ ETHICAL CLINICAL PRACTICE OF FUNCTIONAL BRAIN IMAGING. REPORT OF SOCIETY

OF NUCLEAR MEDICINE BRAIN IMAGING COUNCIL (1996), pp. 1256-1259.

${ }^{125}$ KIEHL (2006), pp. 107-128; KIEHL et al. (2006), pp. 443-453.

126 GAO et al. (2009), p. 815.

${ }^{127}$ FABIAN (2009), pp. 24-34; PUSTILNIK (2009), pp. 183-237; REDDING (2006), pp. 51-127.

${ }^{128}$ EDERSHEIM et al. (2012), p. 187; JONES et al. (2009), p. 1935.
} 


\section{SÁNCHEZ, María: "Primeros pasos de la neuroimagen en el proceso penal estadounidense".}

vertiente clínica, por lo que, como Walker ${ }^{129}$ afirma, la misma podría convertirse en una herramienta poderosa para la mitigación, teniendo en cuenta que algunos trastornos, como los citados de la personalidad, son muy discutidos por la falta de pruebas tangibles (y en la mayoría de ocasiones los jurados piensan que los procesados fingen los síntomas). ${ }^{130}$ Eso sí, siempre que a los datos provenientes de la neuroimagen no se les dé un peso desproporcionado en la decisión del tribunal, como vimos que se respetó en el caso United States v. Gigante, puesto que, aunque la evidencia neurocientífica mostró un bajo nivel de insanity, la misma fue inconsistente con los resultados ofrecidos por otros elementos de prueba, por lo que estos datos neurocientíficos no fueron lo suficientemente convincentes para neutralizar la sospecha de la corte de que el acusado estaba fingiendo sus síntomas.

En relación con la anterior, conviene hacer referencia al temido efecto del "árbol de Navidad" al que aluden los críticos de estas técnicas, según el cual los miembros del jurado se verían excesivamente influenciados por los coloridos escáneres cerebrales y aceptarían la exploración neurocientífica como prueba de autoridad sin tener en cuenta sus déficits y limitaciones. ${ }^{131}$ Un efecto que no es del todo convincente, dado que un análisis en profundidad revela que el paradigma de la estructura/función que, en cambio, suscriben otros autores, sería un enfoque más certero. Según estos, los miembros del jurado a aquello a lo que le darían mayor importancia, con independencia de las coloridas imágenes, sería a los déficits estructurales que en estos estudios se detectan, en contra de los funcionales, debido a la visión mecanicista de la naturaleza que impera en nuestro mundo. ${ }^{132}$ Además, esto explicaría la disparidad de resultados entre los diferentes estudios realizados al respecto, y, sin duda, los reparos que se encuentran, en general, para admitir los trastornos que no derivan de tumores o lesiones localizadas, sino del complejo funcionamiento cerebral.

Ahora bien, a pesar de que las técnicas de neuroimagen en la fase de culpabilidad servirían para dilucidar de forma más exacta los defectos que se encuentran en las áreas cerebrales involucradas en las capacidades cognitivas y afectivas, como vimos, en este momento son normalmente rechazadas por los tribunales norteamericanos. Situación distinta se encuentra, en cambio, en la fase de sentencia, donde suelen ser admitidas con más

\footnotetext{
${ }^{129}$ WALKER (2013), p. 1779.

${ }^{130}$ CARTER (2006), pp. 1265-1287.

${ }^{131}$ Por eso mismo, en el caso United States v. Mezvinsky, el tribunal declaró que este tipo de pruebas solo pueden ser admisibles si la relevancia de la evidencia superaba a su capacidad de inducir a error a los miembros del jurado. Al respecto, consultar: United States v. Mezvinsky, 206 F. Supp. 2 d 661 (E.D. Pa. 2002).

${ }^{132}$ Los estudios que popularmente se citan como ejemplo de los perjudiciales efectos que las técnicas de neuroimagen tendrían son los de GURLEY y MARCUS, WEISBERG, McCABE y CASTEL, McCABE, GREENE y CAHILL o SCHWEITZER. No obstante, autores como AMIRIAN cuestionan la validez de los mismos, especialmente en su vertiente externa, y en esta línea, existen autores que proponen un entendimiento alternativo al respecto, entendiendo que aquello que influiría en el jurado serían las anomalías estructurales frente a las funcionales, como por ejemplo YEON CHOE con su tesis del paradigma estructura/función; como el mismo indica, aunque aquellos autores que advierten del efecto del "árbol de navidad" se basan en los estudios supra citados, se encuentran investigaciones con conclusiones distintas, como por ejemplo, las de GRUBER y DICKERSON, en las que se concluye que el efecto determinante para la apreciación de una disminución de responsabilidad lo tendría la detección de una anormalidad cerebral. Para más información, consultar: AMIRIAN (2013), p. 1006; GREENE (2012), p. 293; GURLEY y MARCUS (2008), pp. 89-90; GRUBER y DICKERSON (2012), p. 938; McCABE, y CASTEL (2008), p. 344; SCHWEITZER y SAKS (2011), p. 596-597; WEISBERG (2008), p. 470; YEON CHOE (2014), p. 1502.
} 


\section{Polít. Crim. Vol. 15, № 29 (Julio 2020), Art. 8, pp. 230-258 \\ [http://politcrim.com/wp-content/uploads/2020/07/Vol15N29A8.pdf]}

facilidad; de hecho, como los últimos estudios ponen de relieve, y con independencia de casos puntuales, la evidencia de daños cerebrales ha sido uno de los factores más importantes en la anulación de sentencias a muerte. Efectivamente, en un reciente estudio empírico en el que se analizaron 800 casos penales estadounidenses en los que se alegaron evidencias científicas en un período de dos décadas, se concluyó que estas pruebas son presentadas de forma general en la fase de sentencia para mitigar la responsabilidad en aquellos juicios donde está en juego la pena de muerte; y en las mismas los trastornos de la personalidad cada vez tienen mayor importancia. ${ }^{133}$ De todos modos, con independencia de lo enunciado, se entiende que estas pruebas podrían evitar gran parte de los problemas a los que actualmente se enfrentan en la fase de culpabilidad si fueran alegadas en la diminished responsability, pese a que, como vimos, en los EUA la misma se circunscribe a delitos de homicidio, y debe demostrarse una clara relación con la conducta enjuiciada, lo que dificulta su progresión. ${ }^{134}$ Por tanto, la propuesta de Morse, que plantea una figura de responsabilidad disminuida general, similar en gran medida a la regulación continental de la semiimputabilidad, a los efectos del presente estudio resulta verdaderamente interesante, puesto que, ante trastornos como los de la personalidad, donde las capacidades cognitivas y afectivas suelen estar parcialmente alteradas, podría ser perfectamente apreciable.

Tal vez los mayores interrogantes que la introducción de estas técnicas despiertan derivan de su repercusión en las garantías ofrecidas por las constituciones de los diferentes estados $^{135}$, o de su misma configuración (puesto que quedaría por resolver si constituyen pruebas testimoniales o físicas). A pesar de ello, neurocientíficos como Sapolsky ${ }^{136}$, o juristas como Redding, ${ }^{137}$ se han mostrado a favor de una nueva neurojurisprudencia que reforme la insanity defense a la luz de los hallazgos de la Neurociencia, si bien hasta el momento estas sugerencias políticas no se han materializado, y sigue siendo muy complicado para los acusados articular una defensa exitosa cuando los acusados presentan trastornos discutidos como los de la personalidad. No obstante, cualquier conocimiento que permita una mayor comprensión del comportamiento humano debería ser tenido en cuenta por el sistema de justicia, pues las técnicas de neuroimagen pueden ser útiles en la legitimación de algunas de las figuras más controvertidas del edificio penal, entre ellas las defensas o eximentes, erigiéndose como un complemento de los instrumentos tradicionales que aumenten la fiabilidad de las decisiones individuales.

\footnotetext{
${ }^{133}$ Como en la investigación citada se concluye, la neuroimagen se utiliza en general para demostrar la existencia de estos daños o disfunciones cerebrales (concretamente, 271 de los 553 casos), así como trastornos de la responsabilidad, mitigando de este modo la responsabilidad, especialmente en aquellos juicios en los que se discute la pena de muerte. DENNO (2015), pp. 517 y ss.

${ }^{134}$ No fue así en el caso Goldstein, dado que el tribunal declaró que la PET que se aportó no podía demostrar de manera concluyente que la esquizofrenia que la defensa alegaba hubiera provocado que el acusado empujara a una joven a las vías del tren, dado que, según el tribunal, esta prueba no probaba el impacto de la esquizofrenia en la cognición y el comportamiento. Al respecto, consultar: People v. Goldstein, 843 N.E.2d 727 (N.Y. App. Div. 2005) En igual sentido: Jackson v. Calderon, 211 F.3d 1148 (9th Cir. 2000). 135 TOVINO (2007), pp. 51 y ss.; HALLIBURTON (2007), p. 309.

${ }^{136}$ SAPOLSKY (2004), pp. 1787-1788, p. 1794.

${ }^{137}$ REDDING (2006), p. 51.
} 


\section{Bibliografía}

AAMODT, Michael y CISTER Heather (2006): "Who Can Best Catch a Liar? A MetaAnalysis of Individual Differences in Detecting Deception", en: Forensic Examiner $\left(n^{\circ} 15,6\right)$.

ABBOTT, Alison (2007): "Abnormal Neuroscience: Scanning Psychopaths", en: Nature (450), pp. 942-944.

AMERICAN MEDICAL ASSOCIATION (2005): Brief of the American Medical Association as Amici Curiae in Support of Respondent.

AMIRIAN, Justin (2013): "Weighing the Admissibility of fMRI Technology Under FRE 403: For the Law, fMRI Changes Everything - and Nothing", en: Fordham Urban Law Journal (Vol. XLI, No. 4).

ANNAS, George (2007): "Foreword: Imagining a New Era of Neuroimaging, Neuroethics, and Neurolaw”, en: Am. J.L. \& Med. (nº 33).

ARONSON, Jay (2007): "Brain Imaging, Culpability and the Juvenile Death Penalty", en: Psychol. Pub. Pol'y \& L. (13).

ARNAUDO, Luca (2010): "Diritto cognitivo. Prolegomeni a una ricerca", en: Politica del Diritto (no 41-1).

BAIRD, Abigail; BARROW, Christy; RICHARD, Molly (2012): "Juvenile NeuroLaw: When It's Good It Is Very Good Indeed, and When It's Bad It's Horrid”, en: Journal of Health Care Law and Policy (Volume 15, Issue 1).

BARTH, Abram S. (2007): "A Double-Edged Sword: The Role of Neuroimaging in Federal Capital Sentencing”, en: Am. J. L. \& Med. (33).

BASKIN, Joseph; EDERSHEIM, Judith; PRICE, Bruce (2007): "Is a picture worth a thousand words? Neuroimaging in the courtroom", en: American Journal of Law \& Medicine (33).

BIRCKHEAD, Tamar (2011): “Symposium: Juvenile Justice Reform 2.0”, en: Journal of Law and Policy (20).

BISHOP, Sonia; JENKINS, Rob; LAWRENCE, Andrew (2007): "Neural processing of fearful faces: Effects of anxiety are gated by perceptual capacity limitations", en: Cerebral Córtex, (17), pp. 595-603.

BOND Jr., Charles; DE PAULO, Bella (2008): "Individual Differences in Detecting Deception: Accuracy and Bias", en: Psychol. Bull (n' 134).

BUSATO, Paulo César (2007): Derecho Penal y acción significativa (Valencia, Tirant lo Blanch).

CANTERO, Raoul G.; KLINE, Robert M. (2009): "Death is Different: The Need for Jury Unanimity in Death Penalty Cases", en: St. Thomas L. Rev. $(22,4)$.

CARTER, Snead (2006): "Neuroimaging And The Courts: Standards And Illustrative Case Index. Emerging Issues in Neuroscience Conference for State and Federal Judges", A Conference Sponsored by the American Association for the Advancement of Science (AAAS), the Federal Judicial Center, the National Center for State Courts, and the Dana Foundation.

CHURCH, Dominique (2012): "Neuroscience in the Courtroom: An International Concern", en: William \& Mary Law Review (n 53(5)).

COLEGIO AMERICANO DE RADIOLOGÍA. Guía Actualizada sobre Radiología.

DEMETRIO CRESPO, Eduardo, (Dir.); MAROTO, Manuel, (Coord.) (2013): Neurociencias y Derecho Penal (Madrid, Edisofer).

DENNO, Deborah W. (2015): "The Myth of the Double-Edged Sword: An Empirical Study of Neuroscience Evidence in Criminal Cases", en: B.C.L. Rev. (56). 
DRESSLER, Joshua (1992): Understanding Criminal Law, $2^{\mathrm{a}}$ ed. (New York: Matthew Bender \& Co.).

EDERSHEIM, Judith; BRENDEL, Rebecca W.; PRICE, Bruce H. (2012): "Neuroimaging, Diminished Capacity and Mitigation", en: SIMPSON, Joseph R. Neuroimaging in Forensic Psychiatry: From the Clinic to the Courtroom, Chapter: 9 (New Jersey, Wiley-Blackwell).

EDERSHEIM, Judith G.; BECK, James C. (2005): "Commentary: Expert Testimony as a Potential Asset in Defense of Capital Sentencing Cases", en: J. Am. Acad. Psychiatry Law (33).

EHRLICH, Paul; FELDMAN, Marcus (2007): “Genes, Environments and Behaviors", en: Daedalus (136).

ERICKSON, Steven (2010): “Blaming the Brain”, en: Minnesota Journal of Law, Science \& Technology (11(1)).

ESPARZA LEIBAR, Iñaki; PLANCHADELL GARGALLO, Andrea; PÉREZ CEBADERA, Maria Ángeles (2013): Introducción al Proceso Penal Federal de los Estados Unidos de Norteamérica (Valencia, Tirant lo Blanch).

BARKOW, Rachel E. (2011): "Federalism and Criminal Law: What the Feds Can Learn from the States", en: Mich. L. Rev. (109).

FABIAN, John M. (2013): "Death Penalty Mitigation and the Role of the Forensic Psychologist", en Law \& Psychol. Rev. (27).

FABIAN, John M. (2009): "Forensic Neuropsychological Assessment and Death Penalty Litigation", en: Champion (33).

FAIGMAN, David (2002): "Is science different for lawyers?", en: Science (vol. 297, Issue 5580).

FAIGMAN, David; MONAHAN, John; SLOBOGIN, Christopher (2014): "Group to Individual (G2i) Inference in Scientific Expert Testimony" en: The University of Chicago Law Review (Volume 81, Number 2).

FARAH, Martha (2002): "Emerging Ethical Issues in Neuroscience", en: Nature Neuroscience $\left(\mathrm{n}^{\circ} 5\right)$.

FARAHANY, Nita (2011): An empirical study of brains and genes in U.S. Criminal Law (Vanderbilt University Law School).

FARWELL, Lawrence A., RICHARDSON, Drew C.; RICHARDSON, Graham M, (2013): "Brain Fingerprinting field studies comparing P300-MERMER and P300 brainwave responses in the detection of concealed information"; en: Cognitive Neurodynamics (vol. 7, issue 4).

FEIGENSON, Neal (2006): "Brain imaging and courtroom evidence: on the admissibility and persuasiveness of fMRI", en: Int. J. Law Context (2).

FEIX, Jeff; WOLBER, Greg (2007): "Intoxication and Settled Insanity: A Finding of Not Guilty by Reason of Insanity”, en: J. Am. Acad. Psychiatry Law (35).

FINGARETTE, Herbert (1972): The Meaning of Criminal Insanity (California, University of California Press).

FOX, Adam R.; KVARAN, Trevor H.; FONTAINE, Reid G. (2012): "Psychopathy and Culpability: How Responsible Is the Psychopath for Criminal Wrongdoing?", en: Law \& Social Inquiry $(38,1)$.

GAO, Yu; GLENN, Andrea; SCHUG, Robert, et al. (2009): "The Neurobiology of Psychopathy: A Neurodevelopmental Perspective”, en: Can. J. Psychiatry (54 (12)).

GARLAND, Brent (Ed.) (2004): Neuroscience and the Law, Brain, Mind and the Scales of Justice (New York: Dana Press). 
GARVEY, Stephen P (1998): “Aggravation and Mitigation in Capital Cases: What do Jurors Think?”, en: Columb. L. Rev. (98), pp. 1538-1576.

GAZZANIGA, Michael (2008): "The Law and Neuroscience", en: Neuron (60).

GRAY, Jeremy (2004): "Integration of Emotion and Cognitive Control", en: Current Directions in Psychol. Sci. (13).

GREENE, Joshua; PAXTON, Joseph (2009): "Patterns of Neural Activity Associated with Honest and Dishonest Moral Decisions”, en: Proc. Nat'1 Acad. Sci. U.S. Am. $\left(n^{\circ} 106\right)$.

GREENE, Edith; CAHILL, Brian S. (2012): "Effects of Neuroimaging Evidence on Mock Juror Decision Making", en: Behav. Sci. L. (30).

GREENE, Joshua; COHEN, Jonathan (2004): "For the Law, Neuroscience Changes Nothing and Everything", en: Phil. Trans. R. Soc. Lond. B. (nº 359).

GRUBER, David; DICKERSON, Jacob A. (2012): "Persuasive Images in Popular Science: Testing Judgments of Scientific Reasoning and Credibility", en: Pub. Understanding Sci. (21).

GRUBER, Staci; YURGELUN-TODD, Deborah (2006): "Neurobiology and the Law: A Role in Juvenile Justice?”, en: Ohio St. J. Crim. L. (3).

GURLEY, Jessica R.; MARCUS, David K. (2008): "The Effects of Neuroimaging and Brain Injury on Insanity Defenses", en: Behav. Sci. \& L. (26).

HALLIBURTON, Christian M. (2007): "Letting Katz Out of the Bag: Cognitive Freedom and Fourth Amendment Fidelity", en: Hastings L.J. (59).

HOFFMAN, Morris (2004): "The Neuroeconomic Path of the Law", en: Phil. Transactions Royal Soc'y London B:Biological Sci. (n $\left.{ }^{\circ} 359\right)$.

HUGHES, Virginia (2010): "Science In Court", en: Nature (Vol. 464).

ILLES, Judy; BIRD, Stephanie (2006): "Neuroethics: a modern context for ethics in neuroscience", en: Trends Neurosci. (29(9)).

JONES, Owen et al. (2014): "Brain Imaging for judges: an introduction to Law and Neuroscience", en: American Judges Association Court Review (50).

JONES, Owen; BROSNAN, Sarah (2008): "Law, Biology, and Property: A New Theory of the Endowment Effect", en: Wm. \& Mary L. Rev. (1935).

JONES, Owen; SHEN, Francis (2011): "Law and Neuroscience in the United States", en: Vanderbilt Public Law Research Paper ( $\left.n^{\circ} 1-5\right)$.

JONES, Owen; SCHALL, Jeffrey; SHEN, Francis (2014): Law \& Neuroscience (New York, Wolters Kluwer Law \& Business).

JONES, Owen (2004): "Law, Evolution, and the Brain: Applications and Open Questions", en: Phil. Transactions Royal Soc'y London B. Biological Sci.

JONES, Owen; BUCKHOLTZ, Joshua W.; SCHALL, Jeffrey D. (2009): "Brain Imaging for legal thinkers: A guide for the perplexed", en: Stanford Technology Law Review (5).

KIEHL, Kent A. (2006): “A Cognitive Neuroscience Perspective on Psychopathy: Evidence for Paralimbic System Dysfunction”, en: Psychiatry Res. (142).

KIEHL, Kent A., BATES, Alan T., LAURENS, Kristin R., et al (2006): "Brain Potentials Implicate Temporal Lobe Abnormalities in Criminal Psychopaths", en: J. Abnormal. Psychol. (115(3)).

LENAMON, Terence (2010): "After Admission of QEEG Brain Map Evidence, Florida Jury Nixes Death Sentence for Grady Nelson", PRWeb. Disponible en: https://www.prweb.com/pdfdownload/4863164.pdf [visitado el 28.02.2019].

LOGOTHETIS, Nikos (2008): "What We Can Do and What We Cannot Do with fMRI", Nature (453).

LYNCH, Michael; McNALLY, Ruth (1999): "Science, common sense and common law: 
courtroom inquires and the public understanding of science", en: Social Epistem (13).

MARONEY, Terry (2010): “Adolescent Brain Science After Graham v. Florida”, en: Notre Dame L. Rev. (86).

MARONEY, Terry (2006): "Emotional Competence, 'Rational Understanding', and the Criminal Defendant", en: Am. Crim. L. Rev (n' 43).

MARTÍNEZ GARAY, Lucía (2016): "Errores conceptuales en la estimación de riesgo de reincidencia. La importancia de diferenciar sensibilidad y valor predictivo, y estimaciones de riesgo absolutas y relativas", en: Revista Española de Investigación Criminológica: REIC ( $\left.{ }^{\circ} 4\right)$.

MELTON, Gary; PETRILA, John; POYTHRESS, Norman; SLOBOGIN, Crhistopher; OTTO, Randy; MOSSMAN, Douglas; CONDIE, Lois (2010): Psychological evaluations for the courts: A handbook for mental health professionals and lawyers (New York, Guilford).

MEYER, Carlin (2009): "Brain, Gender, Law: A Cautionary Tale", New York Law School Law Review, no 53, (2009).

McCABE, David P.; CASTEL, Alan D. (2008): "Seeing is Believing: The Effect of Brain Images on Judgments of Scientific Reasoning", en: Cognition (107) (2008).

MIDGLEY, Mary (2004): “Do We Ever Really Act?”, en: REES, D. y ROSE, S. (Eds.) The New Brain Sciences: Perils and Prospects (Cambridge University Press).

MOBBS, Dean; HAKWAN, Lau; JONES, Owen; FRITH, Christopher (2007): "Law, Responsibility, and the Brain", en: Plos Biology (5).

MOORE, Michael (1984): Law and Psychiatry (Cambridge, Cambridge University Press).

MORENO, Jonathan (2003): "Neuroethics: an agenda for neuroscience and society", en: Nature Rev. (4).

MORIARTY, Jane C (2008): "Flickering Admissibility: Neuroimaging Evidence in the U.S. Courts", en: Behav. Sci. \& L. (26).

MORSE, Stephen (2011): "Avoiding Irrational NeuroLaw Exuberance: A Plea for Neuromodesty", en: Mercer Law Review (62).

MORSE, Stephen; ROSKIES, Adina. (Eds.) (2012): A Primer on Criminal Law and Neuroscience (Oxford University Press).

MORSE, Stephen (2004): "New neuroscience, old problems: legal implications of brain science", en: Cerebrum (6(4)).

MORSE, Stephen (2003): "Diminished Rationality, Diminished Responsibility", en: Ohio State Journal of Criminal Law (1).

OVALLE, David (2010): "Ex-Miami-Dade worker gets life for murder, rape", Miami Herald. December (3).

PARDO, Michael; PATTERSON, Dennis (2010): "Philosophical Foundations of law and neuroscience" en: University of Illinois Law Review (2010).

PATEL, Purvak; MELTZER, Carolyn; MAYBERG, Helen; LEVINE, Kay (2007): "The Role of Imaging in United States Courtrooms", en: Neuroimaging Clinics N. Am. (17).

PESSOA, Luiz; MCKENNA, Mary; GUTIERREZ, Eva; UNGERLEIDER, Leslie (2002): "Neural processing of emotional faces requires attention", en: Proceedings of the National Academy of Sciences.

PHELPS, Elizabeth (2006): "Emotion and cognition: Insights from studies of the human amygdala", en: Annual Review of Psychology (24).

PETTIT, Mark (2007): "fMRI and BF Meet FRE: Brain Imaging and the Federal Rules of Evidence", Am. J.L. \& Med. (33). 
PIÑA ROCHEFORT, Juan Ignacio (2002): La estructura de la teoría del delito en el ámbito jurídico del "common law" (Granada, Comares).

POLDRACK, Russell; FLETCHER, Paul; HENSON, Richard; WORSLEY, Keith; BRETT, Matthew; NICHOLS, Thomas (2008): "Guidelines for Reporting an fMRI Study", en: Neuroimage (40), p. 409.

PUSTILNIK, Amanda C. (2009): "Violence on the brain: a critique of neuroscience in criminal law", en: Wake Forest Law Review (44).

RACINE, Eric, et al. (2005): "fMRI in the Public Eye", en: Nature Revs. Neuroscience, (6).

REDDING, Richard E. (2006): "The brain-disordered defendant: Neuroscience and legal insanity in the twenty-first century", en: American University Law Review, (56).

ROSKIES, Adina (2008): "Neuroimaging and Inferential Distance", en: Neuroethics (1).

ROTH, Sydney B. (2012): "The emergence of neuroscience evidence in Louisiana", en: Tul. L. Rev. (87).

RUSHING, Susan E. (1966): "The Admissibility of Brain Scans in Criminal Trials: The Case of Positron Emission Tomography", en: Court Review (Volume 50).

SAPOLSKY, Robert (2004): "The Frontal Cortex and the Criminal Justice System", en: Phil. Transactions Royal Soc'y London B. (359).

SCHAUER, Frederick (2010): "Can Bad Science Be Good Evidence? Lie Detection, Neuroscience and the Mistaken Conflation of Legal and Scientific Norms", en: Cornell L. Rev. (95).

SCHWEITZER, Nicola J.; SAKS, Michael (2011): "Neuroimage Evidence and the Insanity Defense", en: Behav. Sci. L. (9).

SEIDEN, Jessie A. (2004): "The Criminal Brain: Frontal Lobe Dysfunction Evidence in Capital Proceedings", en: Cap. Defense J., (16 (2)).

SHIPLEY, Stacey; ARRIGO, Bruce (2012): Introduction to Forensic Psychology. Court, Law, Enforcement and Correctional Practices, Third Edition (San Diego, CA: Elsevier).

SHERROD, Taylor; ANDERSON, Harp; TYRON, Elliott (1991) "Neuropsychologists and neurolawyers". En: Neuropsychology (Vol 5(4)).

SIMPSON, Joseph R. (2012): Neuroimaging in Forensic Psychiatry: From the Clinic to the Courtroom, Chapter: 9 (New Jersey, Wiley-Blackwell).

STUNTZ, William J. (2008): “Unequal Justice”, en: Harv. L. Rev. (121).

TOVINO, Stacey (2007): "Imaging Body Structure and Mapping Brain Function: A Historical Approach", en: American Journal of Law \& Medicine (33).

TROUT, J.D. (2008): "Seduction Without Cause: Uncovering Explanatory Neurophilia", en: Trends Cognitive Sci. (12).

URRUELA MORA, Asier (2010): "La Genética como factor relevante a efectos del juicio de imputabilidad penal: estado de la cuestión y perspectiva crítica (Particular consideración de la Sentencia de la Corte de Apelación de Trieste, Italia, de 18 de septiembre de 2009)", en: Revista de derecho y genoma humano ( $\left.\mathrm{N}^{\circ} 32\right)$.

WAGNER, Anthony (2010): “Can Neuroscience Identify Lies?", en: GAZZANIGA, Michael. S.; RAKOFF, Jed S. (Eds.). A Judge's Guide to Neuroscience: A Concise Introduction (Santa Barbara - California, Sage Center for the Study of the Mind).

WALKER, Brett (2013): "When the facts and the law are against you, argue the genes?: A pragmatic analysis of genotyping mitigation defenses for psychopathic defendants in death penalty cases", en: Washington University Law Review, (Vol. 90, Issue 6). 
WEISBERG, Deena; KEIL, Frank; GOODSTEIN, Joshua; RAWSON, Elizabeth; GRAY, Jeremy (2008): "The Seductive Allure of Neuroscience Explanations", en: J. Cognitive Neuroscience (20).

YEON CHOE, So (2014): "Misdiagnosing the Impact of Neuroimages in the Courtroom"; en: UCLA Law Review (61).

\section{Sentencias}

Ake v. Oklahoma, 470 U.S. 68. (1985)

Barefoot v. Estelle, 463 U.S. 880 (1983).

Boyd v. Bert Bell/Pete Rozelle 410 F.3d 1173, 1174 (9th Cir. 2005).

California v. Miguel Carrizalez, (2011) (No. VCF 169926C).

Caro v. Woodford, 280 F.3d 1247 (9th Cir.), cert. denied 536 U.S. 951 (2002)

Coe v. State, 17 S.W.3d 193, 243 (Tenn. 2000).

Cooper v. State, 739 So.2d 82 (Fla, 1999)

Daubert v. Merrell Dow Pharmaceuticals, Inc. 509 U.S. 579 (1993)

Durham v. United States (214 F. 2d862)

Ervin v. State, 531 N.E.2d 186 (Ind. 1988)

Ferrell v. State, 918 So. 2d 163, 175-76 (Fla. 2005)

Finger v. Nevada, 27 P.3d 66 (Nev. 2001).

Fini v. Gen. Motors Corp No. 227592, 2003 WL 1861025, at 2-3 (Mich. Ct. App. Apr. 8, 2003).

Frierson v. Woodford, 463 F.3d 982 (9th Cir. 2006).

Frye v. United States, 293 F. 1013 (D.C. Cir. 1923).

Godinez v. Moran, 509 U.S. 389, 404 (1993).

Graham v. Florida, 560 U.S. 48 (2010)

Hernandez v. Martel, 824 F.Supp. 2d 1025 (CD Cal. 2011)

Hoskins v. State, 702 So. 2d 202, 209 (Fla. 1997).

Hoskins v. State, 735 So.2d 1281 (Fla. 1999)

Idaho v. Winn, 828 P.2d 879 (Idaho 1992)

Indiana v. Edwards, 554 U.S. 164 (2008).

Jackson v. Calderon, 211 F.3d 1148 (9th Cir. 2000).

James v. Ryan, 679 F.3d 780, 784-85 (9th Cir. 2012), vacated, 133 S. Ct. 1579 (2013).

Kansas v. Bethel, 66 P.3d 840 (Kan. 2003)

Leland v. Oregon 343 790, 96LEd1302, 72CtS1002 (1952).

Lockett v. Ohio, 438 U.S. 586 (1978).

Mc Donald v. United States. 114 U.S.App. DCen 124, 312F.2d en 851

McMurtrey v. Ryan, 539 F.3d 1112 (9th Cir. 2008).

McNamara v. Borg 923 F.2d 862 (9th Cir. 1991).

Montreal v. Cowan, 861 P.2d 884 (Mont. 1993)

People v. Ford, WL 236487 (Cal. Ct. App. 2005).

People v. Goldstein, 843 N.E.2d 727 (N.Y. App. Div. 2005)

People v. Holt, 15 Cal.4th 619, 646 (Cal. 1997)

People v. Morgan, 719 N.E.2d 681 (Ill. 1999)

People v. Protsman 105 Cal.Rptr.2d 819.[47]. (2001).

People v. Ramsey, 422 Mich. 500, 375 N.W.2d 297, 71 A.L.R. 4th 661 (1985).

People v. Weinstein, 591 N.Y.S.2d 715 (N.Y. Sup. Ct. 1992).

People v. Yum, 3 Cal.Rptr.3d 855 (Cal Ct. App 2003).

R v. Hanson, EWCA Crim 1142 (2005).

Rogers v. State, 783 So.2d 980 (Fla. 2001). 
Roper v. Simmons, 543 U.S. 551, 578 (2005).

Sexton v. State, 775 So.2d 923, 936 (Fla. 2000).

Smith v. Mullin, 379 F.3d 919, 939 (10th Cir. 2004).

State v. Grady Nelson, No. F05-00846 (11th Fla. Cir. Ct., 4 Dec 2010)

State v. Hurst, 606 So. 2d 965, 968 (La. App. 3 Cir. 1992).

State v. Kinkel, 184 Or. App. 277 (Or. Ct. App. 2002);

State v. Marshall, 27 P.3d 192, 200 (Wa. 2001).

State v. Reid, 213 S.W.3d 792 (Tenn. 2006).

State v. Sopczak, No. 02-KA-235 (La. Ct. App. 2002).

Stewart v. State, 37 So.3d 243, 249 (Fla. 2010); State v. Mercer, 672 S.E.2d 556 (S.C. 2009).

Strickland v. Washington, 466 U.S. 668 (1984).

Tennard v. Dretke, 542 U.S. 274 (2004).

Thompson v. Oklahoma, 487 U.S. 815. (1988).

Trapp v. Spencer, 470 F.3d 53 (1st Cir. 2007).

United States v. Amos (1986, CA8Mo) 803 F2d 419

United States v. Booker, 543 U.S. 220 (2005).

United States v. Brawner (471F. 2d969).

United States v. Byrd (1987, CA8Mo) 834 F2d 145

United States v. Dr. Jihad Kasim. Cause No. 2:07 CR 56. (N.D. Ind. Nov 03, 2008).

United States v. Freeman (1986, CA11Ala) 804 F2d 1574, 22 de las Reglas de la Fed Evid Serv 154.

United States v. Gigante, 982 F.Supp. 140, 159 (1997).

United States v. Hill (1990, NDGa) 750 F Supl 524)

United States v. Mezvinsky, 206 F. Supp. 2d 661 (E.D. Pa. 2002).

United States v. Montgomery, 635 F.3d 1074 (8th Cir. 2011).

United States v. Pryor (1992, CA1Me) 960 F 2d1

United States v. Semrau, 693 F.3d 510 (6th Cir. 2012).

Utah v. Mace, 921 P.2d 1372 (Utah 1996)

Van Middlesworth v. Century Bank \& Trust Co No. 215512, 2000 WL 33421451, at 1-2 (Mich. Ct. App. May 5, 2000). 